Running Head. Need Satisfaction Profiles

\title{
A Person-Centered Representation of Basic Need Satisfaction Balance at Work
}

Nicolas Gillet*, Département de Psychologie, Université de Tours, France

Alexandre J.S. Morin*, Substantive Methodological Synergy Research Laboratory, Department of Psychology, Concordia University, Canada

Frédéric Choisay, Département de Psychologie, Université de Tours, France

Evelyne Fouquereau, Département de Psychologie, Université de Tours, France

* The first two authors (N.G. \& A.J.S.M.) contributed equally to this article and their order was determined at random: Both should thus be considered first authors.

\section{Corresponding author}

Nicolas Gillet,

Université de Tours,

UFR Arts et Sciences Humaines,

Département de psychologie,

3 rue des Tanneurs, 37041 Tours Cedex 1, France.

E-mail: nicolas.gillet@univ-tours.fr

The second author was supported by a grant from the Social Science and Humanity Research Council of Canada (435-2018-0368) in the preparation of this manuscript.

This is the prepublication version of the following manuscript:

Gillet, N., Morin, A. J. S., Choisay, F., \& Fouquereau, E. (2019). A person-centered representation of basic need satisfaction balance at work. Journal of Personnel Psychology. Early view. doi :

$10.1027 / 1866-5888 / \mathrm{a} 000228$

This paper is not the copy of record and may not exactly replicate the authoritative document published in Journal of Personnel Psychology.

\begin{abstract}
This study examines how a global overarching need satisfaction construct, together with three specific dimensions (autonomy, competence, and relatedness needs satisfaction) combine within different profiles of workers among two independent samples $(n=1419$ and $n=677)$. In addition, this research investigates the role of job demands and resources in the prediction of profile membership, and documents the relation between these profiles and maladaptive outcomes (anxiety and physical fatigue). The results revealed four distinct profiles. Job resources (e.g., participation, organizational support, work scheduling autonomy) predicted an increased likelihood of membership into the Normative profile in both samples. The Globally Dissatisfied yet Moderately Autonomous profile was also associated with the highest anxiety levels relative to all other profiles.
\end{abstract}

Key words: Psychological need satisfaction; Latent profiles; Bifactor; Job demands and resources; Burnout 
The satisfaction of employees' psychological needs at work represents an important driver of work motivation, well-being, and performance (Deci, Olafsen, \& Ryan, 2017). Self-determination theory (SDT; Deci \& Ryan, 2000) proposes that the satisfaction of the needs for autonomy (the need to experience a sense of volition and psychological freedom), competence (the need to feel effective), and relatedness (the need to feel connected with others) is crucial to the emergence of self-determined goal-directed behaviors across domains, including work (Deci et al., 2017). While SDT has received strong support from variable-centered studies demonstrating the importance of psychological need satisfaction for employees' functioning, this support remains mainly focused on the isolated effect of each need, without considering the combined effects of autonomy, competence, and relatedness needs satisfaction. In a related way, despite the acknowledgement that individuals might be driven by a combination of multiple forms of needs satisfaction (e.g., Ferrand, Martinent, \& Charry, 2015; Souesme, Martinent, \& Ferrand, 2016), little is known about the typical configurations that characterize these combinations, the organizational factors involved in their emergence, and their effects on work-related outcomes.

Indeed, variable-centered analyses operate under the assumption that all participants are drawn from a single population for which a single set of "average" parameters can be estimated. In contrast, person-centered analyses, such as latent profile analyses (LPA), identify homogeneous subgroups (or profiles) of workers sharing similar configurations of psychological needs satisfaction. The present study adopts such a person-centered approach to identify naturally occurring profiles characterized by distinct configurations of need satisfaction, their determinants, and their outcomes, while also considering the extent to which results would generalize across two independent samples of employees. Indeed, from a more practical standpoint, the ability to rely on person-centered solutions as guides for the development of intervention strategies tailored at distinct profiles of employees (e.g., Meyer \& Morin, 2016) is conditional on the ability to demonstrate that these profiles can be reliably identified across a variety of samples. More precisely, observing similarity means that generic interventions strategies (designed to select, promote, manage, help or support employees based on their profiles) can be developed and expected to generalize to different types of workers, which is a much more parsimonious approach than having to develop strategies targeting different types of profiles for distinct types of workers. More generally, the present research aims to illustrate the utility of innovative statistical procedures by showing how they may help to achieve an improved representation of employees' need satisfaction profiles.

We first reviewed prior studies examining the combined effects of need satisfaction using variable- and person-centered methodologies. Then, we referred to the construct validity of personcentered solutions in order to ascertain that the extracted profiles of participants are meaningful in their own right and can be expected to generalize across samples. Finally, we studied the links between need satisfaction profiles and a set of predictors (job demands and resources) and outcomes (anxiety and physical fatigue) to support a substantive interpretation of the identified profiles.

\section{The Combined Effects of Need Satisfaction}

SDT positions the psychological needs for autonomy, competence, and relatedness as essential nutriments for well-being (Deci \& Ryan, 2000) and positive work outcomes, such as work engagement and job satisfaction (Huyghebaert, Gillet, Fernet et al., 2018). In contrast, when these needs are not satisfied, maladaptive outcomes, such as burnout, are expected (Trépanier, Fernet, \& Austin, 2013). These conclusions hold across a variety of work settings (Gillet, Fouquereau, Forest, Brunault, \& Colombat, 2012). SDT also states that all three needs must be fulfilled for psychological well-being to occur (Deci \& Ryan, 2000). Thus, if only one or two of the three needs are satisfied, employees' functioning would be less optimal than when the three needs are satisfied. Despite evidence suggesting differential relations between the three needs and work outcomes (Trépanier, Fernet, \& Austin, 2016), this hypothesis remains difficult to verify with variable-centered studies given the interrelated nature of the three needs (Bidee et al., 2017; Gillet, Lafrenière, Vallerand, Huart, \& Fouquereau, 2014). Two approaches can be used to study these combined effects of psychological needs satisfaction: Variablecentered analyses of interactions or balance, and person-centered analyses of employees' profiles.

\section{Variable-Centered Analyses}

Variable-centered tests of interaction effects are designed to assess the extent to which the effects of a variable differ as a function of any other variable (e.g., Marsh, Hau, Wen, Nagengast, \& Morin, 2013). In this approach, mutually reinforcing effects would be evidenced by the observation that the 
effects of the satisfaction of each need would increase when the level of satisfaction of the other needs increases. In a first study of interactions effects, Vansteenkiste, Lens, Soenens, and Luyckx (2006) showed that the needs for autonomy, competence, and relatedness all predicted unique variance in students' psychological well-being, vitality, and depression. Autonomy need satisfaction also had a weaker positive effect on vitality and a weaker negative effect on depression when relatedness need satisfaction was high. Thus, as suggested by SDT, the experience of interpersonal intimacy and connection with others appeared to compensate for a lack of ability to function in a volitional manner. In addition, the positive relation between competence need satisfaction and vitality was found to be weaker among students with low levels of autonomy compared to those with high levels of autonomy. Thus, again in line with SDT, the ability to function in a volitional manner seemed to help students maximally benefit from high levels of competence need satisfaction. In a more recent study focusing on leisure activities among adults, Chang (2012) observed a similar mutually reinforcing positive interaction between autonomy and competence need satisfaction in the prediction of self-rated health.

Rather than focusing on interactions, Sheldon and Niemiec (2006) argued that understanding the combined effects of need satisfaction required the consideration of the extent to which the satisfaction of the three needs would be balanced with one another. They argued that two employees with the same global level of need satisfaction might present two very distinct need satisfaction profiles, based on the degree to which satisfaction level was similar across the three needs. Using an additional score reflecting the "balance" among the satisfaction of these three needs, their results showed that students who experienced a balanced level of need satisfaction tended to report higher levels of well-being than other students presenting the same global amount of need satisfaction but a more unbalanced profile. However, although Dysvik, Kuvaas, and Gagné (2013) reported similar effects of need balance in the prediction of workers' intrinsic motivation, they also found that need balance did not account for any additional variance in intrinsic motivation once the effects of need satisfaction levels and of their interactions were taken into account. When considering these results, it is important to note that both studies relied on an indirect measurement of need balance via the calculation of difference scores, known to be particularly sensitive to measurement errors (Edwards, 2002). An additional flaw of Dysvik et al.'s (2013) approach comes from the fact that they added the need balance difference score to a regression equation already incorporating the interactions effects. Yet, these interactions effects are known to incorporate an implicit representation of balance effects (e.g., Cheung, 2009; Edwards, 2009). This statistical redundancy could explain Dysvik et al.'s (2013) observation of the limited added-value of balance effects.

Interestingly, recent psychometric research on the structure of need satisfaction ratings has revealed a more direct way to measure of need balance. More precisely, despite the recognition that a complete assessment of psychological need satisfaction should tap into the needs of autonomy, competence, and relatedness (Bidee, Vantilborgh, Pepermans, Griep, \& Hofmans, 2016; Knight, Patterson, Dawson, \& Brown, 2017), high correlations are typically observed among ratings of autonomy, competence, and relatedness needs satisfaction (Bidee et al., 2017; Gillet et al., 2014). This observation has led many researchers to suggest that employees might experience need satisfaction in a more holistic manner (Huyghebaert, Gillet, Fernet et al., 2018) as a single overarching dimension (Gillet, Forest, Benabou, \& Bentein, 2015; Gillet, Fouquereau, Huyghebaert, \& Colombat, 2015; Jungert, Van den Broeck, Schreurs, \& Osterman, 2018). More recently, studies relying on bifactor models have started to demonstrate that that need satisfaction ratings simultaneously reflect respondents' global levels of need satisfaction across all three needs as well as the more specific levels of satisfaction of their needs for competence, relatedness, and autonomy left unexplained by this global level (Sánchez-Oliva et al., 2017; Tóth-Király, Morin, Bőthe, Orosz, \& Rigó, 2018). In a bifactor model (Chen, West, \& Sousa, 2006), one Global (G) factor underlying the answers to all items (here reflecting balance in the satisfaction of all three needs) and a series of orthogonal Specific (S) factors (here reflecting the degree of imbalance associated with each need when compared to the others) explain the covariance among a set of items. This bifactor representation of need satisfaction has been supported in the work (Bidee et al., 2016; Sánchez-Oliva et al., 2017), educational (Gillet et al., 2018), sport (Brunet, Gunnell, Teixeira, Sabiston, \& Bélanger, 2016), and general life (Tóth-Király et al., 2018) areas, and provides a way to simultaneously obtain a direct explicit estimate of the extent to which the satisfaction of all three needs is balanced for a specific individual (the global component), together with a non-redundant estimate of imbalance in the satisfaction of each need relative to all 
others for a specific individual (i.e., expressed as deviations from that global level).

\section{A Person-Centered Perspective}

Person-centered analyses, such as LPA, are specifically designed to account for the presence of subpopulations characterized by different parameters (Meyer \& Morin, 2016; Morin, 2016). LPA focus on the identification of subgroups characterized by distinct configurations, or profiles, on a set of variables, and are naturally suited to the consideration of the joint effects of variable combinations. More precisely, LPA provide a way to investigate how the various components of need satisfaction will be combined among different types of employees. However, no person-centered research on employees' need satisfaction profiles has so far been conducted in the work domain.

Of direct relevance to the present investigation, Morin and Marsh (2015; also see Morin, Boudrias et al., 2016, 2017) showed that whenever global constructs are assumed to co-exist with specific dimensions assessed from the same set of indicators, failure to control for this global tendency in the context of LPA may mistakenly result in the identification of profiles of employees differing from one another quantitatively (level) rather than qualitatively (shape). More precisely, these authors note that the identification of level-differentiated profiles (i.e., profiles characterized by matching levels across all indicators and differing from one another quantitatively) is generally taken as evidence against the meaningfulness of a person-centered solution, when compared to shape-differentiated profiles (i.e., profiles characterized by a qualitatively different configuration of indicators). However, just like ignoring co-existing global and specific constructs is likely to result in inflated factor correlations or cross-loadings in variable-centered analyses, this ignorance is likely to result in the erroneous estimation of level-differentiated profiles in LPA. These considerations appear to be particularly important to person-centered research focusing on need satisfaction given the aforementioned research evidence that employees ratings of need satisfaction do indeed tend to follow a bifactor structure encompassing both a global (need balance) and specific (need imbalance) components. Following Morin, Boudrias et al.'s $(2016,2017)$ recommendations, the need satisfaction profiles estimated in the present study will thus be estimated on the basis of factor scores taken from preliminary bifactor measurement models. According to these authors, this approach not only provides a way to achieve a better control for measurement errors than relying on scale scores (Skrondal \& Laake, 2001), but it also provides a way to identify profiles differing on the basis of both the global and specific factors.

Despite the fact that no research has ever been done to estimate need satisfaction profiles in the work area, two recent person-centered studies of need satisfaction profiles have been conducted among geriatric populations. In the first of those studies, Souesme et al. (2016) identified three need satisfaction profiles among geriatric patients characterized by (1) low levels of autonomy and competence needs satisfaction, coupled with moderate levels of relatedness need satisfaction (lowmoderate satisfaction profile), (2) high levels of relatedness need satisfaction, coupled with moderate levels of autonomy and competence needs satisfaction (high-moderate satisfaction profile), and (3) high levels of autonomy, competence, and relatedness needs satisfaction (high satisfaction profile). In the second study, Ferrand et al. (2015) similarly identified three need satisfaction profiles among hospitalized elderly people: (1) a high satisfaction profile, (2) a profile characterized by high levels of autonomy and competence needs satisfaction, coupled with moderate levels of relatedness need satisfaction, and (3) a low satisfaction profile.

This study is the first to estimate need satisfaction profiles in the work area, and the first do so while relying on factor scores taken from preliminary bifactor measurement models. Yet, recent person-centered results obtained in the geriatric area, coupled with variable-centered results related to the need balance perspective (Dysvik et al., 2013; Sheldon \& Niemiec, 2006; Vansteenkiste et al., 2006), allow us to propose the following hypotheses:

Hypothesis 1. Employees' need satisfaction at work will be best represented by a relatively small number of profiles (i.e., between three and five).

Hypothesis 2. At least one profile reflecting employees' need satisfaction at work will be characterized by high and matching levels of need satisfaction across dimensions.

Hypothesis 3. Additional profiles reflecting employees' need satisfaction at work will be characterized by well-differentiated configurations of need satisfaction across indicators.

\section{A Construct-Validation Perspective}

As noted by Morin, Meyer, Creusier, and Biétry (2016), it is critical to systematically assess the construct validity of person-centered solutions in order to ascertain that the extracted profiles of participants 
are meaningful in their own right and can be expected to generalize across samples. A way to address these issues is the demonstration that the identified profiles have heuristic and theoretical values, which is best illustrated by the identification of well-differentiated relations between the identified profiles and a series of theoretically-relevant predictors and outcomes, and that they can reliably be replicated across samples (Marsh, Lüdtke, Trautwein, \& Morin, 2009; Morin, 2016).

Generalizability. Person-centered evidence is cumulative in nature, and requires an accumulation of results obtained within distinct samples to differentiate the core subset of profiles that systematically emerges, the peripheral profiles that only emerges in specific situations, and the even less frequent set of profiles that simply reflects random sampling variations (e.g., Morin, 2016; Solinger, Van Olffen, Roe, \& Hofmans, 2013). In the absence of prior person-centered research on need satisfaction profiles at work, it appeared particularly critical for this study to assess the extent to which the identified profiles would generalize across two distinct samples of participants.

Hypothesis 4. The identified profiles reflecting employees' need satisfaction at work will be replicated across two distinct samples of employees.

Job Demands and Resources. According to the job demands-resources model (Bakker \& Demerouti, 2007), a health impairment process is activated by excessive demands that lead to physical and psychological health problems. Job demands refer to those aspects of a job that require sustained physical and/or psychological effort, therefore resulting in physiological and/or psychological costs. In contrast, job resources may help to enhance employees' well-being and to reduce psychological health difficulties as they contribute to achieving goals, reducing the costs associated with job demands, and stimulating personal growth. The effects of job demands (e.g., mental load, workload, role ambiguity) and resources (e.g., information, participation, perceived colleagues support, perceived organizational support, work scheduling autonomy, task identity, and significance) have been examined in relation to burnout, work engagement, and organizational commitment (Bakker, Demerouti, \& Sanz-Vergel, 2014; Brauchli, Schaufeli, Jenny, Füllemann, \& Bauer, 2013). This influence has been shown to occur through personal resources (Xanthopoulou, Bakker, Demerouti, \& Schaufeli, 2007), equity (Hu, Schaufeli, \& Taris, 2013) or recovery (Kinnunen, Feldt, Siltaloppi, \& Sonnentag, 2011). Attention has also been paid to the effects of job demands and resources on need satisfaction (Gillet, Fouquereau et al., 2015; Trépanier et al., 2015). Fernet, Austin, Trépanier, and Dussault (2013) showed that employees' perceptions of role ambiguity negatively predicted their competence need satisfaction.

Despite the well-documented importance of job demands and resources in the work context (Alarcon, 2011), to the best of our knowledge, no person-centered research has examined the effects of job demands and resources on employees' need satisfaction profiles. We thus leave as an open research question the exact differential role of job demands and resources in need satisfaction profiles. However, prior variable-centered studies (Fernet et al., 2013; Trépanier et al., 2015) suggest that job demands and resources should predict membership into need satisfaction profiles. More specifically, higher job demands should predict a higher likelihood of membership into the profiles characterized by lower levels of autonomy, competence, and relatedness needs satisfaction. In contrast, higher job resources should predict a higher likelihood of membership into the profiles characterized by higher levels of autonomy, competence, and relatedness needs satisfaction (Trépanier et al., 2015). Nevertheless, because of the demonstrated benefits of need balance (Dysvik et al., 2013; Sheldon \& Niemiec, 2006; Vansteenkiste et al., 2006), we also expect that higher job resources and lower job demands should predict a higher likelihood of membership into the profiles in which there is a balance across the three needs (i.e., with high levels of global need satisfaction and low specific levels of imbalance in the satisfaction of the needs for autonomy, competence, and relatedness).

Outcomes of Profile Membership. The present study also seeks to assess relations between the need satisfaction profiles and employees' levels of job anxiety and physical fatigue. These two outcome variables were retained based on previous research showing that they present significant associations with employees' need satisfaction (Huyghebaert, Gillet, Lahiani, Dubois-Fleury, \& Fouquereau, 2018; Trépanier et al., 2013). Previous variable-centered research has shown need satisfaction to be associated with a variety of desirable outcomes (e.g., lower anxiety and burnout; see Deci et al., 2017). In addition, numerous studies (Trépanier et al., 2016) report well-differentiated relations between each need and work outcomes. However, research also leads to divergent conclusions regarding the relative importance of each need in the prediction of outcomes. For instance, Sheldon and Niemiec's (2006) results suggest that moderate levels of autonomy need satisfaction are 
not necessarily harmful when combined with equally moderate levels of competence and relatedness needs satisfaction among undergraduate students. In addition, autonomy need satisfaction was less strongly related to well-being when relatedness need satisfaction was high (Vansteenkiste et al., 2006). Given that all of these previous results stem from variable-centered research, we leave as an open research question the exact differential nature of the associations between the need satisfaction profiles and employees' levels of anxiety and physical fatigue. Yet, these previous variable-centered results still allow us to expect that the profile characterized by the highest levels of autonomy, competence, and relatedness needs satisfaction would be associated with the lowest levels of anxiety and physical fatigue. Likewise, the profile characterized by the lowest levels of autonomy, competence, and relatedness needs satisfaction should similarly be associated with the highest levels of anxiety and physical fatigue. Finally, a profile characterized by differentiated scores across specific needs, attesting to need imbalance (e.g., high specific levels of autonomy coupled with low specific levels of competence and relatedness) should be associated with higher levels of anxiety and physical fatigue than a profile characterized by matching levels across all indicators (i.e., high levels on the global need satisfaction factors coupled with low levels of imbalance evidenced by average scores on the specific autonomy, competence, and relatedness factors).

\section{Participants and Procedure}

\section{Method}

Sample 1. This study was conducted in the French Air Force. Soldiers received information about the study via the intranet network of the French Air Force, and were then sent an e-mail inviting them to complete an online survey. Each soldier also received a letter explaining the study's purposes, a consent form stressing that participation was voluntary, and a link to the online survey. A sample of 580 contract and 839 career soldiers (1107 men and 312 women) participated in this study. Respondents were aged between 20 and 62 years $(M=36.61, S D=8.06)$, had an average tenure of 16.29 years $(S D=8.44)$ in the French Air Force and of 3.56 years $(S D=3.26)$ in their position.

Sample 2. Research assistants distributed a paper-based questionnaire to a convenience sample of 677 workers (309 men; 367 women; 1 participant did not indicate his/her gender) from organizations (e.g., public hospitals, industries, sales, and services) located in France. In each organization, participants received a survey packet including the questionnaire, a cover letter explaining the study's purposes, and a consent form stressing that participation was anonymous and voluntary.

Questionnaires took approximately 20 minutes to complete. Completed questionnaires were returned to the research assistants. Respondents were aged between 18 and 61 years $(M=37.56, S D=12.79)$, had an average tenure of 10.19 years $(S D=10.66)$ in their organization and of 6.65 years $(S D=8.11)$ in their position. A total of 557 participants were full-time workers (82.3\%). Thirty-eight participants (5.6\%) had no diploma, 211 completed vocational training (31.2\%), 187 completed high school (27.6\%), 231 completed university (34.1\%), and 10 did not indicate their education level (1.5\%).

\section{Measures}

Need Satisfaction. Need satisfaction was measured with fifteen items from a measure initially developed in French by Gillet, Rosnet, and Vallerand (2008). In the present study, these items were contextualized with the referent "At work...", and were rated on a 7-point scale ranging from 1 (strongly disagree) to 7 (strongly agree). Five items assessed the need for competence ( $\alpha$ in Sample 1 $=.85 ; \alpha$ in Sample 2 = .86; e.g., "I feel like I am able to meet the demands of the tasks that I have to perform"), five items referred to the need for autonomy ( $\alpha$ in Samples 1 and $2=.89$; e.g., "I have the opportunity to make decisions about the tasks that I have to perform"), and five items measured the need for relatedness ( $\alpha$ in Sample $1=.83$; $\alpha$ in Sample 2 = .80; e.g., "I get along well with the people whom I interact with"). Previous studies showed good psychometric properties for this scale in work settings (e.g., Gillet et al., 2012).

Job demands and resources (Sample 1: Predictors). Mental load (4 items, $\alpha=.87$; e.g., "Do you have to give continuous attention to your work?"), workload (4 items, $\alpha=.85$; e.g., "Do you have too much work to do?"), role ambiguity ( 4 items, $\alpha=.81$; e.g., "Do you know exactly for what you are responsible and which areas are not your responsibility?", reversed item), information (4 items, $\alpha=$ .85; e.g., "Does your work give you the opportunity to check on how well you are doing your work?"), participation ( 4 items, $\alpha=.88$; e.g., "Can you participate in decisions affecting issues related to your work?"), and perceived colleagues support ( 4 items, $\alpha=.90$; e.g., "Can you count on your colleagues when you encounter difficulties in your work?") were measured with six subscales from a measure 
developed and validated in French by Lequeurre, Gillet, Ragot, and Fouquereau (2013). Responses were provided on a 7-point response scale ranging from 1 (never) to 7 (always).

Job resources (Sample 2: Predictors). Work scheduling autonomy (3 items, $\alpha=.73$; e.g., "The job allows me to plan how I do my work"), task identity (4 items, $\alpha=.78$; e.g., "The job allows me to complete work I start"), and significance (4 items, $\alpha=.78$; e.g., "The job has a large impact on people outside the organization") were measured via scales from the French version of the Work Design Questionnaire (Bigot et al., 2014; Morgeson \& Humphrey, 2006). Items were rated on a 7-point scale (1- strongly disagree to 7- strongly agree).

Perceived organizational support (Sample 2: Predictor). Perceived organizational support was assessed using 8 items ( $\alpha=.87$; e.g., "My organization really cares about my well-being") from the French version (Gillet, Colombat, Michinov, Pronost, \& Fouquereau, 2013; Gillet, Huart, Colombat, $\&$ Fouquereau, 2013) of Eisenberger, Huntington, Hutchison, and Sowa's (1986) measure. All items were rated on a 1 (strongly disagree) to 7 (strongly agree) response scale.

Anxiety (Sample 2: Outcome). A 5-item subscale $(\alpha=.85)$ from the French version (Gillet, Fouquereau, Lafrenière, \& Huyghebaert, 2016) of the Job-Anxiety-Scale (Linden, Muschalla, \& Olbrich, 2008) was employed (e.g., "Colleagues or family have already told me that I am worrying too much about my work") to assess anxiety. Participants responded to items on a 7-point Likert-scale ranging from 1 (totally disagree) and 7 (totally agree).

Physical fatigue (Sample 2: Outcome). Physical fatigue was assessed with 6 items ( $\alpha=.92$; e.g., "I feel tired") from the French version (Sassi \& Neveu, 2010) of the Shirom and Melamed's (2006) burnout measure. Responses were provided on a 7-point scale (1- never to 7- always).

\section{Preliminary Analyses}

Analyses

Mixture models (including LPA) are often estimated using mean or sum scores as profile indicators. Although latent factors controlled for measurement errors (i.e., models where the items are used to estimate factors, themselves used as profile indicators) provide a stronger approach (e.g., Bollen, 1989), fully-latent mixture models are rarely seen (e.g., Morin, Scalas, \& Marsh, 2015). Indeed, given their computational complexity, it is often impossible to estimate fully-latent mixture models. An alternative, which is becoming more frequent recently, is to rely on factor scores saved from preliminary measurement models (e.g., Gillet, Morin, \& Reeve, 2017; Kam, Morin, Meyer, \& Topolnytsky, 2016). Factor scores do not explicitly control for measurement errors the way latent variables do, but provide a partial control for measurement errors by giving more weight to items presenting lower residuals (Skrondal \& Laake, 2001), and preserve the nature of the measurement model (i.e., measurement invariance and bifactor structure) better than scale scores (Morin, Meyer et al., 2016). This is the approach taken in the present study for profile indicators, predictors, and outcomes.

In addition, given the aforementioned mounting evidence regarding the superiority of a bifactor representation of need satisfaction ratings (Sánchez-Oliva et al., 2017; Tóth-Király et al., 2018), firstorder and bifactor models were systematically contrasted. As expected, our results supported the superiority of a bifactor representation of need satisfaction ratings. Yet, for comparison purposes, factor scores from preliminary first-order and bifactor measurement models were used as inputs for the analyses. These factor scores were saved from multi-group models of measurement invariance (Millsap, 2011) to ensure the comparability of the results across samples. Extensive details on these measurement models, their measurement invariance, and composite reliability are reported in the online supplements. All analyses relied on Mplus 8.0's (Muthén \& Muthén, 2017) robust maximum likelihood (MLR) estimator, and Full Information Maximum Likelihood (FIML; Enders, 2010) to handle missing responses (Sample 1: 0\%; Sample 2: 0.00-1.62\%).

\section{Person-Centered Analyses}

LPA were first estimated separately in each sample using the need satisfaction factor scores as profile indicators to verify whether the same number of profiles would be extracted in both samples (e.g., Morin \& Wang, 2016). In each sample, we examined solutions including 1 to 8 latent profiles in which the means of the need satisfaction factor scores were freely estimated in all profiles. Despite the advantages of models in which the indicators' variances are also freely estimated in all profiles (Morin, Maïano et al., 2011), these models tended to converge on improper solutions or not at all. This suggests the inadequacy of these models and their overparameterization, and the superiority of our more 
parsimonious models (Chen, Bollen, Paxton, Curran, \& Kirby, 2001). LPA were conducted using 5000 random sets of start values, 1000 iterations, and retaining the 200 best solutions for final optimization (Hipp \& Bauer, 2006). The procedure used to determine the optimal number of profiles, as well as the similarity in the profile solutions across samples, is described in the online supplements.

\section{Predictors and Outcomes of Profile Membership}

The results reported in the online supplements supported the similarity of the profiles estimated (in terms of number, structure, and size) across samples. This most "similar" profile was retained in order to test associations between the profiles, predictors, and outcomes in order to ensure the comparability of results. Because predictors and outcomes differed across samples, separate models had to be estimated. To ensure that the final, most similar, LPA solution remained unchanged by the addition of predictors and outcomes (Diallo, Morin, \& Lu, 2017; Marsh et al., 2009; Morin, Morizot, Boudrias, \& Madore, 2011), sample-specific solutions aligned with the final retained multi-group solution were defined using the manual three-step approach described by Asparouhov and Muthén (2014; also see Morin \& Litalien, 2017). Multinomial logistic regressions were conducted separately in each sample to test the relations between the predictors and profile membership. In Sample 2, outcomes were also incorporated into the final solution. Outcome levels were contrasted using a model-based approach proposed by Lanza, Tan, and Bray (2013) and implemented through the Auxiliary (DCON) function (Asparouhov \& Muthén, 2014). Predictors and outcomes were incorporated to these models as factors scores saved from preliminary measurement models estimated separately in each sample. In these models, each predictor and outcome was defined as a simple correlated CFA factor. One a priori correlated uniqueness was added to the model estimated in Sample 2 to account for the negative wording of two of the perceived organizational support items (Marsh, Scalas, \& Nagengast, 2010). In both samples, these preliminary measurement models resulted in an acceptable level of model fit $(\mathrm{CFI} / \mathrm{TLI} \geq .90 ; \mathrm{RMSEA} \leq .06)$. Parameter estimates from these preliminary measurement models are reported in Tables S5 (Sample 1) and S6 (Sample 2) of the online supplements, and the correlations among all variables used in both samples are reported in Table S7 (Sample 1) and S8 (Sample 2) of these online supplements. It is interesting to note that estimates of composite reliability obtained in these preliminary measurement models were fully satisfactory for all variables (Sample 1: $\omega=.819$ to .910; Sample 2: $\omega=.749$ to .918$)$.

\section{Latent Profile Solutions}

\section{Results}

In line with Hypothesis 1, the class enumeration procedure and tests of profile similarity described in the online supplement supported a solution including four profiles per sample for the LPA solution based on bifactor factor scores. These profiles presented the same structure and relative sizes across samples, thus supporting Hypothesis 4. However, within-profile variation on the relatedness S-factor, but not on the other factors, were found to be slightly higher in Sample 2. For comparison purposes, the 4-profile solution was also retained for models based on first-order factor scores, and tests of profile similarity conducted on this solutions converged on identical conclusions. These models were thus retained for interpretation, and are graphically illustrated in Figures 1 (bifactor) and 2 (firstorder). As noted above, these solutions were characterized by the same profile structure and size across samples. Parameter estimates from these models are reported in Table S11 of the online supplements. As expected, the solution based on first-order factor scores resulted in substantively uninteresting profiles presenting almost pure level differences, revealing a very small profile characterized by extremely low levels of need satisfaction (Profile 1: 1.44\%), two large profiles characterized by average (Profile 2: 40.35\%) or high (Profile 4: 41.02\%) levels of need satisfaction, and one moderately large profile characterized by low levels of need satisfaction (17.18\%). In contrast, the solution based on bifactor factor scores resulted in profiles presenting clear shape differences. This observation is aligned with Morin, Boudrias et al.'s $(2016,2017)$ observation that relying on bifactor factor scores helps to extract profiles that can differ from one another both in terms of this global construct (here the global level of need satisfaction), but also based on their specific levels of autonomy, competence, and relatedness needs satisfaction. For this reason, we retained the LPA solution based on bifactor factor scores as our final solution. For this solution, the results also reveal a high level of classification accuracy of participants into their most likely profile in both samples (reported in Table S12 of the online supplements), varying from 82.3\% to 94.7\% in Sample 1, and from $72.1 \%$ to $94.1 \%$ in Sample 2. 
The solution obtained when using bifactor factor scores is illustrated in Figure 1. A first noteworthy observation lies in the identification of a Normative profile (Profile 1), representing $77.13 \%$ of the employees. The label Normative was retained to reflect the fact that this profile not only characterized the majority of employees, but also reflected a subpopulation of employees whose global levels of need satisfaction are slightly above average (about .3 SD higher than the sample average), whereas their specific levels of autonomy, competence, and relatedness satisfaction are similarly close to the average. The identification of such a profile suggested that the basic psychological needs of most employees tended to be globally met at work and to display a strong level of balance across each of the three needs. In contrast, the remaining profiles were characterized not only by moderately low (Profile 2) to very low (Profiles 3 and 4) global levels of need satisfaction, but also by a strong imbalance in the degree of satisfaction of each specific need. Thus, members of Profile 2 were characterized by very low levels of satisfaction of their specific need for autonomy, but by moderately high levels of satisfaction of their specific needs for competence and relatedness. This Globally Dissatisfied yet Moderately Competent and Connected profile characterized $11.87 \%$ of the employees. In contrast, members of Profile 3 were characterized by low levels of satisfaction of their specific needs for autonomy and competence, but by very high levels of satisfaction of their specific need for relatedness. This Globally Dissatisfied yet Highly Connected profile characterized 3.34\% of the employees. Finally, members of Profile 4 were characterized by very low levels of satisfaction of their specific need for relatedness, but by average to moderately high levels of satisfaction of their specific needs for autonomy and competence. This Globally Dissatisfied yet Moderately Autonomous profile characterized $7.66 \%$ of the employees. More generally, these results supported Hypotheses 2 and 3.

Predictors of Profile Membership. Associations between predictors and profile membership are reported in Table 1. Before considering specific results, it is noteworthy that these predictors, when taken together, were able to achieve a statistically significant differentiation between all pairs of profiles. More precisely, in Sample 1, mental load predicted an increased likelihood of membership in the Globally Dissatisfied yet Moderately Competent and Connected profile (2) relative to all other profiles. Role ambiguity predicted an increased likelihood of membership into the Globally Dissatisfied yet Moderately Competent and Connected (2) and Globally Dissatisfied yet Highly Connected (3) profiles relative to the Normative (1) one. In contrast, the ability to participate in decisions predicted an increased likelihood of membership into the Normative (1) and Globally Dissatisfied yet Moderately Autonomous (4) profiles relative to the Globally Dissatisfied yet Moderately Competent and Connected (2) and Globally Dissatisfied yet Highly Connected (3) profiles. Perceptions of colleagues support predicted an increased likelihood of membership into all profiles relative to the Globally Dissatisfied yet Moderately Autonomous (4) profile. Finally, workload and information were unrelated to profile membership.

In Sample 2, perceptions of organizational support predicted an increased likelihood of membership into the Normative (1) and Globally Dissatisfied yet Moderately Competent and Connected (2) profiles relative to the Globally Dissatisfied yet Moderately Autonomous (4) profile. This predictor was also associated with an increased likelihood of membership into the Normative (1) profile relative to the Globally Dissatisfied yet Moderately Competent and Connected (2) profile. Work scheduling autonomy predicted an increased likelihood of membership into the Normative (1) profile relative to all other profiles, whereas neither task identity nor significance presented any statistically significant association with the likelihood of profile membership.

Outcomes of Profile Membership. The associations between profile membership and the outcomes obtained in Sample 2 are reported in Table 2. These analyses reveal that the highest anxiety levels were associated with the Globally Dissatisfied yet Moderately Autonomous profile (4) relative to all other profiles, which could not be differentiated from one another in terms of anxiety. In contrast, levels of physical fatigue were the highest in the Globally Dissatisfied yet Moderately Autonomous (4) and Globally Dissatisfied yet Highly Connected (3) profiles, which could not be differentiated from one another, followed by the Globally Dissatisfied yet Moderately Competent and Connected profile (2), with the lowest levels observed among the Normative profile (1).

\section{Discussion}

Relying on a recent bifactor operationalization of need satisfaction at work (Sánchez-Oliva et al., 2017), we sought to identify profiles of employees characterized by distinct configurations of need satisfaction. To do so, we relied on a proper disaggregation of employees' ratings of their global levels 
of need satisfaction from more specific ratings of imbalance related to the satisfaction of the need for autonomy, competence, and relatedness relative to this global level of need satisfaction.

\section{Characteristics of Need Satisfaction Profiles}

Morin, Boudrias et al. $(2016,2017)$ demonstrated the importance of adopting a proper variablecentered measurement model as a starting point for person-centered analyses. Importantly, they showed that failure to take into account construct-relevant psychometric multidimensionality related to the presence of a bifactor measurement structure could lead to the estimation of latent profiles in which shape differences are minimized and level differences artificially inflated. Indeed, when profiles were estimated based on first-order factor scores, the results revealed profiles presenting almost pure level differences (similar to results previously reported in the geriatric context by Ferrand et al., 2015). In contrast, when the profiles were estimated based on bifactor factor scores, our results revealed much clearer shape differences. More precisely, our results revealed four well-differentiated need satisfaction profiles: (a) Normative; (b) Globally Dissatisfied yet Moderately Competent and Connected; (c) Globally Dissatisfied yet Highly Connected; and (d) Globally Dissatisfied yet Moderately Autonomous. The identification of a large (77.1\%) Normative profile is interesting and suggests that, for the majority of the sample, global levels of need satisfaction remain satisfactory and balanced with the specific needs (autonomy, competence, and relatedness). This result is well-aligned with the results from Morin, Boudrias et al. $(2016,2017)$ who also identified the presence of a dominant normative profile characterized by moderate levels of well-being (2017) or psychological health (2016) across indicators. Apart from this profile characterized by balanced levels of need satisfaction across specific needs and a slightly above average level of global need satisfaction, it is interesting to note that all other profiles are characterized both by discrepant levels of need satisfaction across needs, and by low global levels of need satisfaction, supporting Sheldon and Niemiec's (2006) assertion of the importance of achieving balanced levels of need satisfaction.

Generally, these profiles support the value of a finer-grained representation of need satisfaction incorporating both the global extent to which all three needs are met, and the specificity associated with each need over and above this global level (need imbalance, expressed as deviations from the global level), rather than simply focusing on a global score of need satisfaction (Vansteenkiste et al., 2006). Importantly, our results also showed that these profiles presented a well-differentiated pattern of associations with the two outcomes considered in this study (i.e., anxiety and physical fatigue).

\section{Effects of Need Satisfaction Profiles on Work Outcomes}

To better understand the meaning and the psychological processes involved in these profiles, it is helpful to consider their associations with the two outcomes considered in this study. Specifically, the lowest levels of physical fatigue were observed in the Normative (1) profile, which was the profile characterized by the highest global level of need satisfaction, coupled with the most balanced need satisfaction profile. Based on prior theoretical developments (Sheldon \& Niemiec, 2006) and results (Sánchez-Oliva et al., 2017; Tóth-Király et al., 2018), this result demonstrates the key role of employees' need satisfaction balance in the prediction of work outcomes.

One might wonder about the non-significant differences between the Normative profile and the Globally Dissatisfied yet Moderately Competent and Connected and Globally Dissatisfied yet Highly Connected ones in terms of anxiety. Similarly, the Globally Dissatisfied yet Moderately Autonomous profile appeared to be the least desirable one from an outcomes perspective. When we compare these three globally dissatisfied profiles, it is interesting to note that the least desirable one is associated with the lowest levels of relatedness need satisfaction, whereas both the Globally Dissatisfied yet Moderately Competent and Connected and Globally Dissatisfied yet Highly Connected profiles present high levels of relatedness need satisfaction. These results thus suggest that high levels of relatedness need satisfaction could somehow help to buffer the negative effects of low global levels of need satisfaction. This interpretation is consistent with the theoretically positive role ascribed to relatedness need satisfaction (Vansteenkiste et al., 2006), and the idea that relatedness need satisfaction leads to positive outcomes by helping the internalization process of work-related rules and regulations (Dysvik et al., 2013). Managers should thus focus their efforts in helping to increase relatedness need satisfaction, prior to any other needs, among globally dissatisfied workers.

Finally, the Globally Dissatisfied yet Moderately Competent and Connected profile was associated with lower levels of physical fatigue than the Globally Dissatisfied yet Highly Connected profile. It is noteworthy that the key difference between these two profiles appears to lie in the 
achievement of a more balanced level of need satisfaction across at least two of the needs (competence and relatedness) in the first of these profiles. This result thus suggests that competence need satisfaction might also be helpful, particularly in combination with relatedness need satisfaction. This observation is aligned with the results from previous studies showing that employees who believe in their capabilities to organize and execute their job tasks display lower levels of burnout (Consiglio, Borgogni, Alessandri, \& Schaufeli, 2013). Employees with high levels of competence need satisfaction persevere when faced with difficulties and tend to interpret demands as challenges rather than hindrances or uncontrollable events. They have also optimistic feelings about their performance and their own personal achievements (Ventura, Salanova, \& Llorens, 2015). It thus appears to be better for globally dissatisfied employees to find a way to satisfy their specific need for competence, as doing so may contribute to preserve their emotional resources (Hobfoll, 1989).

More generally, and as mentioned above, these results confirm that specific needs tend to present well-differentiated relations with outcomes when global levels of need satisfaction are considered. They point out the importance of exploring synergistic relations between the three needs and argue for the added-value of jointly considering the global and specific levels of need satisfaction. However, our results suggest that some of the compensatory effects described above are limited to one outcome (anxiety) without generalizing to the other one (physical fatigue). Sánchez-Oliva et al. (2017) demonstrated the nomological validity of global (balance) and specific (imbalance) ratings of need satisfaction in relation to burnout components (emotional exhaustion, depersonalization, and professional efficacy). Their findings revealed that global levels of need balance were negatively associated to all burnout components. They also showed that specific levels of imbalance in the satisfaction of the need for competence (S-factor: having one's need for competence satisfied more than one's global levels of need satisfaction) were negatively related to depersonalization, and positively related to professional efficacy, whereas imbalance in relatedness need satisfaction was negatively related to emotional exhaustion. No such effects were found in relation to imbalance in autonomy need satisfaction. Such results suggest that the combined effects of global and specific levels of need satisfaction may differ as a function of the outcomes under study. This observation reinforces the importance for future research to consider a broader range of desirable (e.g., organizational citizenship behaviors, organizational commitment) and undesirable (e.g., workaholism, work-family conflict) outcomes in order to better understand the mechanisms at play in explaining these differential effects. In addition, future studies should examine how the effects of balance in need satisfaction change as a function of the imbalance related to autonomy, competence, and relatedness.

\section{Predictors of Employees' Need Satisfaction Profiles}

The present study was finally designed to investigate the role of job demands and resources in the prediction of profile membership. To our knowledge, no research has yet considered the factors that contribute to the development of employees' need satisfaction profiles. The present results first showed that job demands such as role ambiguity predicted a decreased likelihood of membership into the Normative profile, while job resources (e.g., participation, organizational support, work scheduling autonomy) predicted an increased likelihood of membership into this profile. This finding is in line with research showing that job demands tend to be associated with lower levels of need satisfaction (Gillet, Fouquereau et al., 2015; Trépanier et al., 2015) and negative outcomes (Bakker et al., 2014) given that they negatively relate to equity (Hu et al., 2013) and recovery (Kinnunen et al., 2011). In contrast, job resources are associated with higher levels of need satisfaction (Fernet et al., 2013) and positive outcomes (Brauchli et al., 2013) as they have positive influence on employees' recovery experiences (Kinnunen et al., 2011). Furthermore, perceptions of organizational and colleagues support also predicted a decreased likelihood of membership into the least desirable Globally Dissatisfied yet Moderately Autonomous profile when compared to the other globally dissatisfied profiles characterized by higher levels of relatedness need satisfaction. This result is in line with past studies showing that perceived organizational and colleagues support foster relatedness need satisfaction as they tend to be associated with lower interpersonal conflicts at work (Eisenberger \& Stinglhamber, 2011). Other investigations also demonstrated that perceived organizational and colleagues support tended to positively relate to psychological need satisfaction (Gillet et al., 2012).

\section{Limitations and Directions for Future Research}

The present study has limitations. First, we used self-report measures that can be impacted by social desirability and self-report biases. We thus encourage researchers to conduct additional research 
using more objective turnover data as well as informant-reported (e.g., supervisor) measures of performance as ultimate outcomes. Second, although our treatment of some variables as predictors or outcomes was based on theoretical considerations (e.g., Deci et al., 2017), our design did not allow us to rule out the possibility of reverse causality, reciprocal influence, or spurious associations. Future longitudinal research should devote more attention to the identification of the true directionality of the associations among predictors, outcomes, and profiles. It would also be important for future research to better consider the mechanisms involved in both the formation and consequences of need satisfaction profiles. Third, future studies may contribute to the literature by adopting a longitudinal design and addressing the joint issues of within-person and within-sample profile stability (Gillet et al., 2017; Kam et al., 2016). More precisely, it would be interesting to examine whether the need satisfaction profiles identified in the current study change in terms of number, structure, variability, size, and outcomes across time (within-sample stability) and whether membership into the different need satisfaction profiles remain stable (within-person stability). Future research may also consider the possible mechanisms at play in explaining these potential profile transitions. Furthermore, it would be interesting for further studies to examine whether a profile characterized by high levels of global need satisfaction balance and low specific levels of imbalance in the satisfaction of the needs for autonomy, competence, and relatedness presents the greatest levels of stability over time. Fourth, we only considered job demands and resources as possible predictors of need satisfaction profiles. It would be interesting for future research to consider a more diversified set of determinants of need satisfaction profiles (e.g., proactive personality, job crafting, organizational culture, transformational leadership). Finally, our reliance on a sample of soldiers (Sample 1) and a convenience sample of workers (Sample 2) makes it hard to assess the extent to which these samples can be considered to be representative of more general populations of workers. It would remain important for future research to rely on more diversified (in terms of cultures, languages, and professions) and representative samples.

\section{Practical Implications}

From a practical perspective, our results suggest that managers should be particularly attentive to employees displaying low global levels of need satisfaction, and especially to those who also display low levels of relatedness need satisfaction (Globally Dissatisfied yet Moderately Autonomous) as these workers appeared to be particularly at risk for a variety of work difficulties, including anxiety and fatigue. Interestingly, our results revealed that perceiving high levels of organizational and colleagues support was associated with a lower likelihood of membership into that least desirable profile. Therefore, practitioners and human resources managers should try to promote organizational and colleagues support in the workplace in order to increase employees' need satisfaction and reduce their psychological health difficulties. Among ways to achieve this objective, top management might promote a supportive culture, for instance, by providing employees the resources or materials they need to perform their job effectively, by reducing work overload, and by promoting justice and fairness in terms of policy implementation and rewards distribution (Eisenberger \& Stinglhamber, 2011). Recently, Gonzalez-Morales, Kernan, Becker, and Eisenberger (2018) also developed and provided evidence for the efficacy of a brief support training program including four basic strategies (i.e., benevolence, sincerity, fairness, and experiential processing). Finally, in order to foster a climate of support among colleagues, managers may implement informal mentoring activities, as well as help to organize informal social events aiming to encourage the development of stronger social ties (Newman, Thanacoody, \& Hui, 2012). In the existing literature, numerous studies have also shown that autonomy-supportive behaviors were positively related to psychological need satisfaction (Gillet et al., 2012). Thus, having managers displaying higher levels of autonomy-supportive behaviors could be associated with higher levels of need satisfaction among employees.

\section{References}

Alarcon, G.M. (2011). A meta-analysis of burnout with job demands, resources, and attitudes. Journal of Vocational Behavior, 79, 549-562. http://doi.org/10.1016/j.jvb.2011.03.007

Asparouhov, T., \& Muthén, B. (2014) Auxiliary variables in mixture modeling: Three-step approaches using Mplus. Structural Equation Modeling, 21, 329341. http://doi.org/10.1080/10705511.2014.915181

Bakker, A.B., \& Demerouti, E. (2007). The job demands-resources model: State of the art. Journal of Managerial Psychology, 22, 309-328. http://doi.org/10.1108/02683940710733115 
Bakker, A.B., Demerouti, E., \& Sanz-Vergel, A.I. (2014). Burnout and work engagement: The JD-R approach. Annual Review of Organizational Psychology \& Organizational Behavior, 1, 389-411. http://doi.org/10.1146/annurev-orgpsych-031413-091235

Bidee, J., Vantilborgh, T., Pepermans, R., Griep, Y., \& Hofmans, J. (2016). Temporal dynamics of need satisfaction and need frustration. Two sides of the same coin? European Journal of Work and Organizational Psychology, 25, 900-913. http://doi.org/10.1080/1359432X.2016.1176021

Bidee, J., Vantilborgh, T., Pepermans, R., Willems, J., Jegers, M., \& Hofmans, J. (2017). Daily motivation of volunteers in healthcare organizations: Relating team inclusion and intrinsic motivation using self-determination theory. European Journal of Work and Organizational Psychology, 26, 325-336. http://doi.org/10.1080/1359432X.2016.1277206

Bigot, L., Fouquereau, E., Lafrenière, M.-A., Gimenes, G., Becker, C., \& Gillet, N. (2014). Analyse préliminaire des qualités psychométriques d'une version française du Work Design Questionnaire. Psychologie du Travail et des Organisations, 20, 203-232.

Bollen, K.A. (1989). Structural equations with latent variables. New York, NY: John Wiley \& Sons.

Brauchli, R., Schaufeli, W.B., Jenny, G.J., Füllemann, D., \& Bauer, G.F. (2013). Disentangling stability and change in job resources, job demands, and employee well-being - A three-wave study on the job demands-resources model. Journal of Vocational Behavior, 83, 117-129. http:// doi.org/10.1016/j.jvb.2013.03.003

Brunet, J., Gunnell, K.E., Teixeira, P., Sabiston, C.M., \& Bélanger, M. (2016). Should we be looking at the forest or the trees? Overall psychological need satisfaction and individual needs as predictors of physical activity. Journal of Sport \& Exercise Psychology, 38, 317-330. http://doi.org/10.1123/jsep.2016-0256

Chang, L.-C. (2012). An interaction effect of leisure self-determination and leisure competence on older adults' self-rated health. Journal of Health Psychology, 17, 324-332. http:// doi.org/10.1177/1359105311415727

Chen, F., Bollen, K., Paxton, P., Curran, P., \& Kirby, J. (2001). Improper solutions in structural question models. Sociological Methods \& Research, 29, 468-508. http://doi.org/10.1177/0049124101029004003

Chen, F.F., West, S.G., \& Sousa, K.H. (2006). A comparison of bifactor and second-order models of quality of life. Multivariate Behavioral Research, 41, 189-225. http://doi.org/10.1207/s15327906mbr4102_5

Cheung, M.W.-L. (2009). Comparison of methods for constructing confidence intervals of standardized indirect effects. Behavior Research Methods, 41, 425-438. http://doi.org/10.3758/BRM.41.2.425

Consiglio, C., Borgogni, L., Alessandri, G., \& Schaufeli, W.B. (2013). Does self-efficacy matter for burnout and sickness absenteeism? The mediating role of demands and resources at the individual and team levels. Work \& Stress, 27, 22-42. http://doi.org/10.1080/02678373.2013.769325

Deci, E.L., \& Ryan, R.M. (2000). The "what" and "why" of goal pursuits: Human needs and the selfdetermination of behavior. Psychological Inquiry, 11, 227-268. http://doi.org/10.1207/S15327965PLI1104_01

Deci, E.L., Olafsen, A., \& Ryan, R.M. (2017). Self-determination theory in work organizations: The state of a science. Annual Review of Organizational Psychology \& Organizational Behavior, 4, 19-43. http://doi.org/10.1146/annurev-orgpsych-032516-113108

Diallo, T.M.O, Morin, A.J.S., \& Lu, H. (2017). The impact of total and partial inclusion or exclusion of active and inactive time invariant covariates in growth mixture models. Psychological Methods, 22, 166-190. http://doi.org/10.1037/met0000084

Dysvik, A., Kuvaas, B., \& Gagné, M. (2013). An investigation of the unique, synergistic and balanced relationships between basic psychological needs and intrinsic motivation. Journal of Applied Social Psychology, 43, 1050-1064. http://doi.org/10.1111/jasp.12068

Edwards, J.R. (2002). Alternatives to difference scores: Polynomial regression analysis and response surface methodology. In F. Drasgow \& N.W. Schmitt (Eds.), Advances in measurement and data analysis (pp. 350-400). San Francisco, CA: Jossey-Bass.

Edwards, J.R. (2009). Latent variable modeling in congruence research: Current problems and future directions. Organizational Research Methods, 12, 34-62. http://doi.org/10.1177/1094428107308920 
Eisenberger, R., Huntington, R., Hutchison, S., \& Sowa, D. (1986). Perceived organizational support. Journal of Applied Psychology, 71, 500-507. http://doi.org/10.1037/0021-9010.71.3.500

Eisenberger, R., \& Stinglhamber, F. (2011). Perceived organizational support: Fostering enthusiastic and productive employees. Washington, DC: American Psychological Association.

Enders, C. (2010). Applied missing data analysis. New York, NY: Guilford.

Fernet, C., Austin, S., Trépanier, S.-G., \& Dussault, M. (2013). How do job characteristics contribute to burnout? Exploring the distinct mediating roles of perceived autonomy, competence, and relatedness. European Journal of Work and Organizational Psychology, 22, 123-137. http://doi.org/10.1080/1359432X.2011.632161

Ferrand, C., Martinent, G., \& Charry, A. (2015). Satisfaction of basic psychological needs, depressive symptoms and apathy in hospitalized elderly. Canadian Journal of Behavioural Science, 47, 59-67. http://doi.org/10.1037/a0037419

Gillet, N., Colombat, P., Michinov, E., Pronost, A.-M., \& Fouquereau, E. (2013). Procedural justice, supervisor autonomy support, work satisfaction, organizational identification, and job performance: The mediating role of need satisfaction and perceived organizational support. Journal of Advanced Nursing, 69, 2560-2571. http://doi.org/10.1111/jan.12144

Gillet, N., Forest, J., Benabou, C., \& Bentein, K. (2015). The effects of organizational factors, psychological need satisfaction and thwarting, and affective commitment on workers' well-being and turnover intentions. Le Travail Humain, 78, 119-140. http://doi.org/10.3917/th.782.0119

Gillet, N., Fouquereau, E., Forest, J., Brunault, P., \& Colombat, P. (2012). The impact of organizational factors on psychological needs and their relations with well-being. Journal of Business and Psychology, 27, 437-450. http://doi.org/10.1007/s10869-011-9253-2

Gillet, N., Fouquereau, E., Huyghebaert, T., \& Colombat, P. (2015). The effects of job demands and organizational resources through psychological need satisfaction and thwarting. The Spanish Journal of Psychology, 18, Article E28. http://doi.org/10.1017/sjp.2015.30

Gillet, N., Fouquereau, E., Lafrenière, M.-A. K., \& Huyghebaert, T. (2016). Examining the roles of work autonomous and controlled motivations on satisfaction and anxiety as a function of role ambiguity. The Journal of Psychology, 150, 644-655. http://doi.org/10.1080/00223980.2016.1154811

Gillet, N., Huart, I., Colombat, P., \& Fouquereau, E. (2013). Perceived organizational support, motivation, and engagement among police officers. Professional Psychology: Research and Practice, 44, 46-55. http://doi.org/10.1037/a0030066

Gillet, N., Lafrenière, M.-A.K., Vallerand, R.J., Huart, I., \& Fouquereau, E. (2014). The effects of autonomous and controlled regulation of performance-approach goals on well-being: A process model. British Journal of Social Psychology, 53, 154-174. http://doi.org/10.1111/bjso.12018

Gillet, N., Morin, A., Huyghebaert, T., Burger, L., Maillot, A., Poulin, A., \& Tricard, E. (2018). University students' need satisfaction trajectories: A growth mixture analysis. Learning and Instruction. Early view. http://doi.org/10.1016/j.learninstruc.2017.11.003

Gillet, N., Morin, A.J.S., \& Reeve, J. (2017). Stability, change, and implications of student motivation profiles: A latent transition analysis. Contemporary Educational Psychology, 51, 222-239. http://doi.org/10.1016/j.cedpsych.2017.08.006

Gillet, N., Rosnet, E., \& Vallerand, R.J. (2008). Development of a basic need satisfaction scale in the sport context. Canadian Journal of Behavioural Science, 40, 230-237. http://doi.org/10.1037/a0013201

Gonzalez-Morales, M., Kernan, M.C., Becker, T.E., \& Eisenberger, R. (2018). Defeating abusive supervision: Training supervisors to support subordinates. Journal of Occupational Health Psychology, 23, 151-162. http://doi.org/10.1037/ocp0000061

Hipp, J.R., \& Bauer, D.J. (2006). Local solutions in the estimation of growth mixture models. Psychological Methods, 11, 36-53. http://doi.org/10.1037/1082-989X.11.1.36

Hobfoll, S.E. (1989). Conservation of resources: A new attempt at conceptualizing stress. American Psychologist, 44, 513-524. http://doi.org/10.1037/0003-066X.44.3.513

Hu, Q., Schaufeli, W.B., \& Taris, T. (2013). Does equity mediate the effects of job demands and job resources on work outcomes? An extension of the job demands-resources model. Career Development International, 18, 357-376. http://doi.org/10.1108/CDI-12-2012-0126

Huyghebaert, T., Gillet, N., Fernet, C., Lahiani, F.-J., Chevalier, S., \& Fouquereau, E. (2018). 
Investigating the longitudinal effects of surface acting on managers' functioning through psychological needs. Journal of Occupational Health Psychology, 23, 207-222. http://doi.org/10.1037/ocp0000080

Huyghebaert, T., Gillet, N., Lahiani, F.-J., Dubois-Fleury, A., \& Fouquereau, E. (2018). Psychological safety climate as a human resource development target: Effects on workers functioning through need satisfaction and thwarting. Advances in Developing Human Resources, 20, 169-181. http://doi.org/10.1177/1523422318756955

Jungert, T., Van Den Broeck, A., Schreurs, B., \& Osterman, U. (2018). How colleagues can support each other's needs and motivation: An intervention on employee work motivation. Applied Psychology: An International Review, 67, 3-29. http://doi.org/10.1111/apps.12110

Kam, C., Morin, A.J.S., Meyer, J.P., \& Topolnytsky, L. (2016). Are commitment profiles stable and predictable? A latent transition analysis. Journal of Management, 42, 1462-1490. http://doi.org/10.1177/0149206313503010

Kinnunen, U., Feldt, T., Siltaloppi, M., \& Sonnentag, S. (2011). Job demands-resources model in the context of recovery: Testing recovery experiences as mediators. European Journal of Work and Organizational Psychology, 20, 805-822. http://doi.org/10.1080/1359432X.2010.524411

Knight, C., Patterson, M.G., Dawson, J., and Brown, J. (2017). Building and sustaining work engagement - a participatory action intervention to increase work engagement in nursing staff. European Journal of Work and Organizational Psychology, 26, 634-649. http://doi.org/10.1080/1359432X.2017.1336999

Lanza S.T., Tan X., \& Bray B.C. (2013). Latent class analysis with distal outcomes: A flexible model-based approach. Structural Equation Modeling, 20, 1-26. http://doi.org/10.1080/10705511.2013.742377

Lequeurre, J., Gillet, N., Ragot, C., \& Fouquereau, E. (2013). Validation of a French questionnaire to measure job demands and resources. International Review of Social Psychology, 26, 93-124.

Linden, M., Muschalla, B., \& Olbrich, D. (2008). Die Job-Angst-Skala. Ein Fragebogen zur Erfassung arbeitsplatzbezogener Angste. Zeitschrift für Arbeits- und Organisationspsychologie, 52, 126-134. http://doi.org/10.1026/0932-4089.52.3.126

Marsh, H.W., Hau, K.-T., Wen, Z., Nagengast, B., \& Morin, A.J.S. (2013). Moderation. In T.D. Little (Ed.), Oxford handbook of quantitative methods, Vol. 2 (pp. 361-386). New York, NY: Oxford University.

Marsh, H.W., Lüdtke, O., Trautwein, U., \& Morin, A.J.S. (2009). Classical latent profile analysis of academic self-concept dimensions: Synergy of person- and variable-centered approaches to theoretical models of self-concept. Structural Equation Modeling, 16, 191-225. http://doi.org/10.1080/10705510902751010

Marsh, H.W., Scalas, L.F., \& Nagengast, B. (2010). Longitudinal tests of competing factor structures for the Rosenberg self-esteem scale: Traits, ephemeral artifacts, and stable response styles. Psychological Assessment, 22, 366-381. http://doi.org/10.1037/a0019225

Meyer, J.P., \& Morin, A.J.S. (2016). A person-centered approach to commitment research: Theory, research, and methodology. Journal of Organizational Behavior, 37, 584-612. http://doi.org/10.1002/job.2085

Millsap, R.E. (2011). Statistical approaches to measurement invariance. New York: Taylor \& Francis.

Morgeson, F.P., \& Humphrey, S.E. (2006). The Work Design Questionnaire (WDQ): Developing and validating a comprehensive measure for assessing job design and the nature of work. Journal of Applied Psychology, 91, 1321-1339. http://doi.org/10.1037/0021-9010.91.6.1321

Morin, A.J.S. (2016). Person-centered research strategies in commitment research. In J.P. Meyer (Ed.), The handbook of employee commitment (p. 490-508). Cheltenham: Edward Elgar.

Morin, A.J.S., Boudrias, J.-S., Marsh, H.W., Madore, I., \& Desrumaux, P. (2016). Further reflections on disentengling shape and level effects in person-centered analyses: An illustration exploring the dimensionality of psychological health. Structural Equation Modeling, 23, 438-454. http://doi.org/10.1080/10705511.2015.1116077

Morin, A.J.S., Boudrias, J.-S., Marsh, H.W., McInerney, D.M., Dagenais-Desmarais, V., Madore, I., \& Litalien, D. (2017). Complementary variable- and person-centered approaches to the dimensionality of psychometric constructs: Application to 
psychological wellbeing at work. Journal of Business and Psychology, 32, 395-419. http://doi.org/10.1007/s10869-016-9448-7

Morin, A.J.S., \& Litalien, D. (2017). Longitudinal tests of profile similarity and latent transition analyses. Montreal, QC: Substantive Methodological Synergy Research Lab. smslabstats.weebly.com/uploads/1/0/0/6/100647486/lta_distributional_similarity_v02.pdf

Morin, A.J.S., Maïano, C., Nagengast, B., Marsh, H.W., Morizot, J., \& Janosz, M. (2011). Growth mixture modeling of adolescents trajectories of anxiety: The impact of untested invariance assumptions on substantive interpretations. Structural Equation Modeling, 18, 613-648. http://doi.org/10.1080/10705511.2011.607714

Morin, A.J.S., \& Marsh, H.W. (2015). Disentangling shape from levels effects in person-centred analyses: An illustration based university teacher multidimensional profiles of effectiveness. Structural Equation Modeling, 22, 39-59. http://doi.org/10.1080/10705511.2014.919825

Morin, A.J.S., Meyer, J.P., Creusier, J., \& Biétry, F. (2016). Multiple-group analysis of similarity in latent profile solutions. Organizational Research Methods, 19, 231-254. http://doi.org/10.1177/1094428115621148

Morin, A.J.S., Morizot, J., Boudrias, J.-S., \& Madore, I. (2011). A multifoci person-centered perspective on workplace affective commitment: A latent profile/factor mixture analysis. Organizational Research Methods, 14, 58-90. http://doi.org/10.1177/1094428109356476

Morin, A., Scalas, L.F \& Marsh, H.W. (2015). Tracking the elusive actual-ideal discrepancy model within latent subpopulations. Journal of Individual Differences, 36, 65-72. http://doi.org/10.1027/1614-0001/a000157

Morin, A.J.S., \& Wang, C.K.J. (2016). A gentle introduction to mixture modeling using physical fitness performance data. In N. Ntoumanis \& N. Myers (Eds.), An introduction to intermediate and advanced statistical analyses for sport and exercise scientists (pp. 195-220). UK: Wiley.

Muthén, L.K., \& Muthén, B. (2017). Mplus user's guide. Los Angeles, CA: Muthén \& Muthén.

Newman, A., Thanacoody, R., \& Hui, W. (2012). The effects of perceived organizational support, perceived supervisor support and intra-organizational network resources on turnover intentions: A study of Chinese employees in multinational enterprises. Personnel Review, 41, 56-72. http://doi.org/10.1108/00483481211189947

Sánchez-Oliva, D., Morin, A.J.S., Teixeira, P.J., Carraça, E.V., Palmeira, A.L., \& Silva, M.N. (2017). A bifactor exploratory structural equation modeling representation of the structure of the Basic Psychological Needs at Work Scale. Journal of Vocational Behavior, 98, 173-187. http://doi.org/10.1016/j.jvb.2016.12.001

Sheldon, K.M., \& Niemiec, C.P. (2006). It's not just the amount that counts: Balanced need satisfaction also affects well-being. Journal of Personality and Social Psychology, 91, 331-341. http://doi.org/10.1037/0022-3514.91.2.331

Shirom, A., \& Melamed, S. (2006). A comparison of the construct validity of two burnout measures in two groups of professionals. International Journal of Stress Management, 13, 176-200. http://doi.org/10.1037/1072-5245.13.2.176

Skrondal, A., \& Laake, P. (2001). Regression among factor scores. Psychometrika, 66, 563-576. http://doi.org/10.1007/BF02296196

Solinger, O.N., Van Olffen, W., Roe, R.A., \& Hofmans, J. (2013). On becoming (un) committed: A taxonomy and test of newcomer onboarding scenarios. Organization Science, 24, 1640-1661. http://doi.org/10.1287/orsc.1120.0818

Souesme, G., Martinent, G., \& Ferrand, C. (2016). Perceived autonomy support, psychological needs satisfaction, depressive symptoms and apathy in French hospitalized older people. Archives of Gerontology and Geriatrics, 65, 70-78. http://doi.org/10.1016/j.archger.2016.03.001

Tóth-Király, I., Morin, A.J.S., Bőthe, B., Orosz, G., \& Rigó, A. (2018). Investigating the multidimensionality of need fulfillment: A bifactor exploratory structural equation modeling representation. Structural Equation Modeling, 25, 267-286. http://doi.org/10.1080/10705511.2017.1374867

Trépanier, S.-G., Fernet, C., \& Austin, S. (2013). Workplace bullying and psychological health at work: The mediating role of satisfaction of needs for autonomy, competence and relatedness. Work \& Stress, 27, 123-140. http://doi.org/10.1080/02678373.2013.782158 
Trépanier, S.-G., Fernet, C., \& Austin, S. (2016). Longitudinal relationships between workplace bullying, basic psychological needs, and employee functioning: A simultaneous investigation of psychological need satisfaction and frustration. European Journal of Work and Organizational Psychology, 25, 690-706. http://doi.org/10.1080/1359432X.2015.1132200

Trépanier, S.-G., Forest, J., Fernet, C., \& Austin, S. (2015). On the psychological and motivational processes linking job characteristics to employee functioning: Insights from self-determination theory. Work \& Stress, 29, 286-305. http://doi.org/10.1080/02678373.2015.1074957

Vansteenkiste, M., Lens, W., Soenens, B., \& Luyckx, K. (2006). Autonomy and relatedness among Chinese sojourners and applicants: Conflictual or independent predictors of well-being and adjustment? Motivation and Emotion, 30, 273-282. http://doi.org/10.1007/s11031-006-9041-x

Ventura, M., Salanova, M., \& Llorens, S. (2015). Professional self-efficacy as a predictor of burnout and engagement: The role of challenge and hindrance demands. The Journal of Psychology: Interdisciplinary and Applied, 149, 277-302. http://doi.org/10.1080/00223980.2013.876380

Xanthopoulou, D., Bakker, A., Demerouti, E., \& Schaufeli, W. (2007). The role of personal resources in the job demands-resources model. International Journal of Stress Management, 14, 121-141. http://doi.org/10.1037/1072-5245.14.2.121

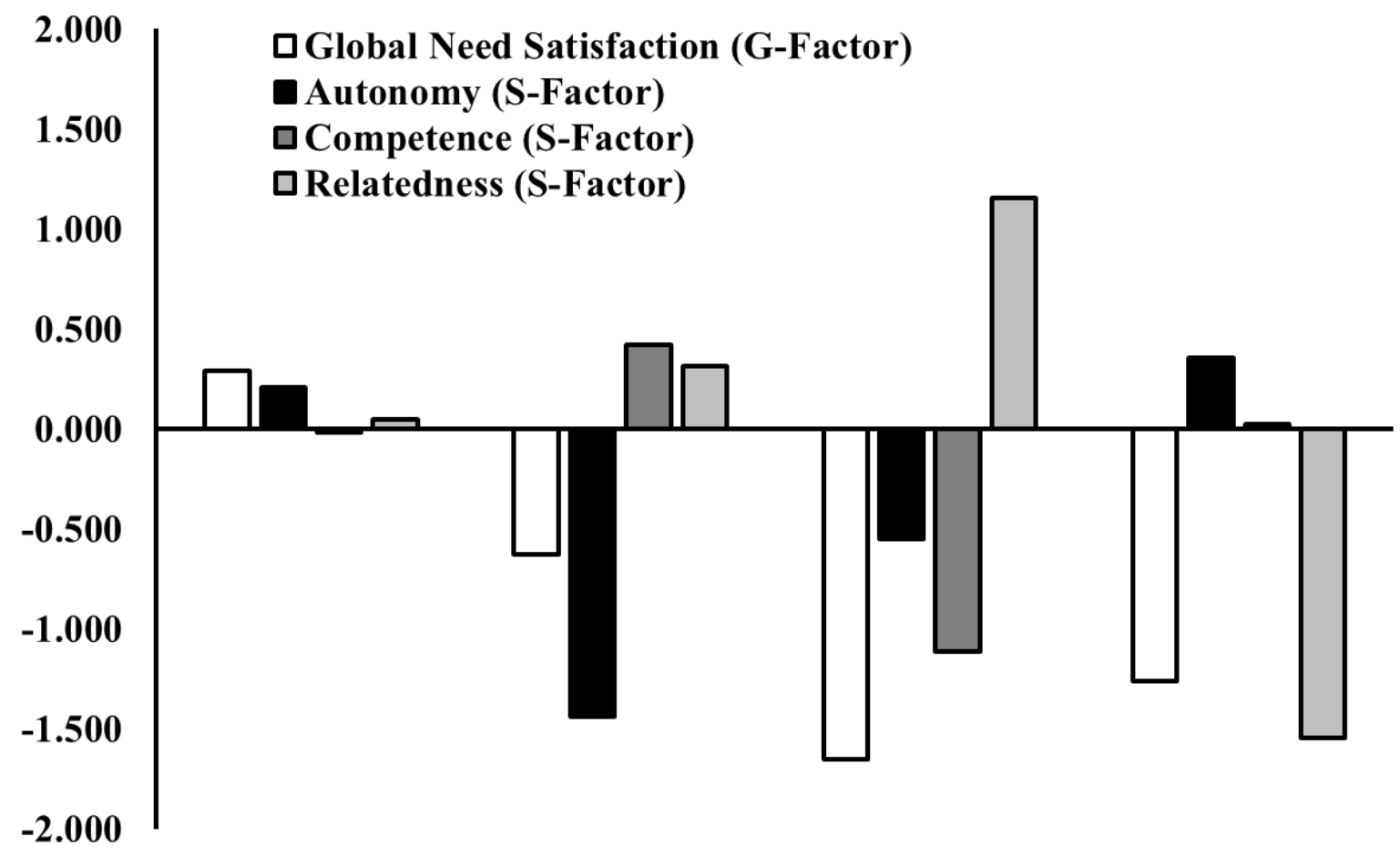

Profile 1 (77.13\%)Profile 2 (11.87\%) Profile 3 (3.34\%) Profile 4 (7.66\%)

Figure 1. Final 4-Profile Solution Based on Bifactor Factor Scores

Note. The global need satisfaction G-factor reflects respondents' global levels of balance in the satisfaction of all three needs; The specific autonomy, relatedness, and competence S-factors reflect imbalance in the satisfaction of all three needs when compared to the others (specific levels of need satisfaction left unexplained by the G-factor); Profile indicators are estimated from factor scores with a $M$ of 0 and a $S D$ of 1; Profile 1: Normative profile; Profile 2: Globally Dissatisfied yet Moderately Competent and Connected profile; Profile 3: Globally Dissatisfied yet Highly Connected profile; and Profile 4: Globally Dissatisfied yet Moderately Autonomous profile. 


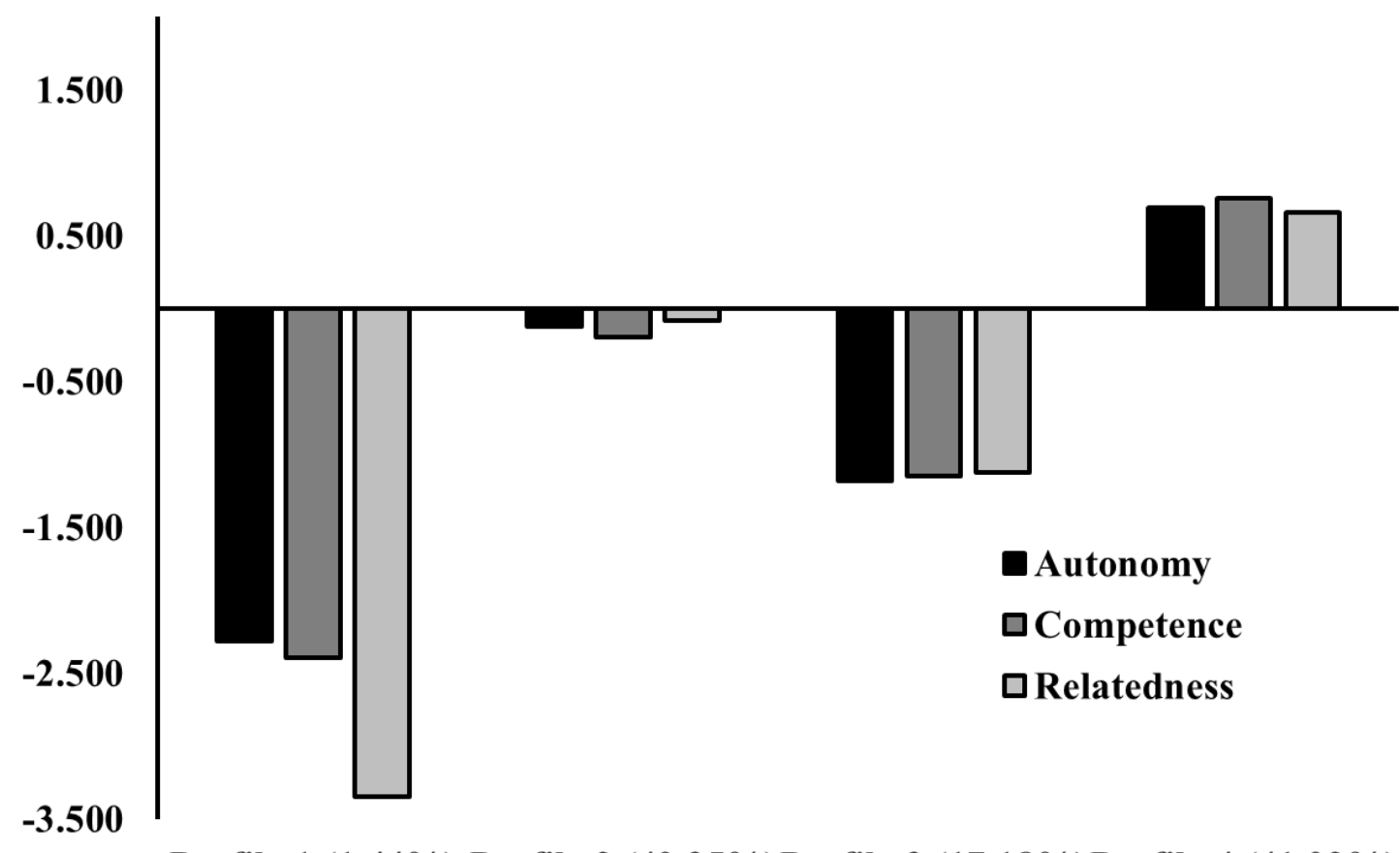

Profile 1 (1.44\%) Profile 2 (40.35\%)Profile 3 (17.18\%)Profile 4 (41.02\%)

Figure 2. Comparison 4-Profile Solution Based on First-Order Factor Scores

Note. Profile indicators are estimated from factor scores with a $M$ of 0 and a $S D$ of 1 . 


\section{Table 1}

Results from Multinomial Logistic Regressions for the Effects of the Predictors on Profile Membership

\begin{tabular}{|c|c|c|c|c|c|c|}
\hline & Latent Profi & & Latent Profi & & Latent Profil & \\
\hline & Coef. (SE) & OR & Coef. (SE) & OR & Coef. (SE) & OR \\
\hline Sample 1 & & & & & & \\
\hline Mental Load & $.190(.354)$ & 1.209 & $.881(.428)^{*}$ & 2.414 & $-.018(.454)$ & .982 \\
\hline Workload & $-.390(.369)$ & .677 & $-.576(.430)$ & .562 & $-.075(.471)$ & .928 \\
\hline Information & $-.257(.359)$ & .774 & $-.014(.455)$ & .986 & $-.313(.487)$ & .731 \\
\hline Participation & $.555(.411)$ & 1.743 & $-1.485(.515)^{* *}$ & .226 & $-2.166(.557)^{* *}$ & .115 \\
\hline Colleagues Support & $2.184(.398) * *$ & 8.883 & $2.176(.558) * *$ & 8.811 & $1.983(.523)^{* *}$ & 7.263 \\
\hline Role Ambiguity & $-.459(.339)$ & .632 & $-.045(.384)$ & .956 & $.319(.431)$ & 1.375 \\
\hline Sample 2 & & & & & & \\
\hline Scheduling Autonomy & $.815(.300)^{* *}$ & 2.259 & $-.289(.343)$ & .749 & $-1.092(.829)$ & .336 \\
\hline Significance & $.343(.254)$ & 1.410 & $.194(.269)$ & 1.215 & $-.255(.455)$ & .775 \\
\hline Task Identity & $.224(.283)$ & 1.251 & $.377(.271)$ & 1.457 & $.601(.392)$ & 1.824 \\
\hline Organizational Support & $1.396(.284) * *$ & 4.039 & $.555(.277)^{*}$ & 1.742 & $.802(.491)$ & 2.230 \\
\hline & Latent Profi & & Latent Profi & & Latent Profil & \\
\hline & Coef. (SE) & OR & Coef. (SE) & OR & Coef. (SE) & \\
\hline Sample 1 & & & & & & \\
\hline Mental Load & $.207(.345)$ & 1.230 & $.899(.363)^{*}$ & 2.457 & $-.692(.229) * *$ & .501 \\
\hline Workload & $-.315(.402)$ & .730 & $-.501(.426)$ & .606 & $.185(.208)$ & 1.203 \\
\hline Information & $.056(.396)$ & 1.058 & $.299(.422)$ & 1.349 & $-.243(.238)$ & .784 \\
\hline Participation & $2.721(.498) * *$ & 15.196 & $.680(.524)$ & 1.974 & $2.041(.276)^{* *}$ & 7.698 \\
\hline Colleagues Support & $.201(.346)$ & 1.223 & $.193(.384)$ & 1.213 & $.008(.281)$ & 1.008 \\
\hline Role Ambiguity & $-.778(.310)^{*}$ & .459 & $-.364(.318)$ & .695 & $-.414(.200)^{*}$ & .661 \\
\hline Sample 2 & & & & & & \\
\hline Scheduling Autonomy & $1.907(.810)^{*}$ & 6.733 & $.803(.860)$ & 2.232 & $1.104(.295) * *$ & 3.016 \\
\hline Significance & $.598(.455)$ & 1.818 & $.449(.497)$ & 1.567 & $.149(.270)$ & 1.161 \\
\hline Task Identity & $-.377(.381)$ & .686 & $-.224(.397)$ & .799 & $-.152(.272)$ & .859 \\
\hline Organizational Support & $.594(.444)$ & 1.811 & $-.247(.453)$ & .781 & $.841(.209) * *$ & 2.319 \\
\hline
\end{tabular}




\section{Table 2}

Associations between Profile Membership and the Outcomes (Sample 2)

\begin{tabular}{lcccc}
\hline & $\begin{array}{c}\text { Profile } 1 \\
\mathrm{M}[\mathrm{CI}]\end{array}$ & $\begin{array}{c}\text { Profile 2 } \\
\mathrm{M}[\mathrm{CI}]\end{array}$ & $\begin{array}{c}\text { Profile 3 } \\
\mathrm{M}[\mathrm{CI}]\end{array}$ & $\begin{array}{c}\text { Profile } 4 \\
\mathrm{M}[\mathrm{CI}]\end{array}$ \\
\hline Anxiety & $-.069[-.145 ; .007]$ & $.019[-.179 ; .217]$ & $-.051[-.461 ; .359]$ & $.756[.440 ; 1.072]$ \\
Physical fatigue & $-.138[-.216 ;-.060]$ & $.255[.049 ; .461]$ & $.746[.311 ; 1.181]$ & $.756[.476 ; 1.036]$ \\
\hline
\end{tabular}

Note. M: mean; CI: 95\% confidence interval; outcomes are estimated from factor scores with mean of 0 and a standard deviation of 1; Profile 1: Normative profile; Profile 2: Globally Dissatisfied yet Moderately Competent and Connected profile; Profile 3: Globally Dissatisfied yet Highly Connected profile; and Profile 4: Globally Dissatisfied yet Moderately Autonomous profile. 
Online Supplemental Materials for:

A Person-Centered Representation of Basic Need Satisfaction Balance at Work

\begin{abstract}
Authors' note:
These online technical appendices are to be posted on the journal website and hot-linked to the manuscript. If the journal does not offer this possibility, these materials can alternatively be posted on one of our personal websites (we will adjust the in-text reference upon acceptance).

We would also be happy to have some of these materials brought back into the main manuscript, or included as published appendices if you deem it useful. We developed these materials to provide additional technical information and to keep the main manuscript from becoming needlessly long.
\end{abstract}




\section{Need Satisfaction Measurement Models Brief Introduction to the Bifactor Exploratory Structural Equation Modeling Framework and Applicability to the Study of Need Satisfaction}

When assessing the structure of responses obtained to typical psychometric measures, the confirmatory factor analysis (CFA) approach provides a way to assess the extent to which our a priori representations match the structure of responses obtained on an instrument, and even to compare alternative representations of the data based on objective fit assessment procedures. However, CFA relies on the independent cluster assumption that the latent constructs are unidimensional. More precisely, CFA assumes that ratings obtained on any indicator reflect, or correspond, to scores on a single factor. This assumption has recently been shown to be overly stringent, and often unrealistic, for many psychometric measures (e.g., Marsh, Morin, Parker, \& Kaur, 2014). Morin and colleagues (Morin, Arens, \& Marsh, 2016; Morin, Arens, Tran, \& Caci, 2016) note that when conceptuallyrelated constructs (e.g., autonomy, competence, and relatedness) are assessed within the same instrument, construct-relevant psychometric multidimensionality needs to be explicitly taken into account. Construct-relevant psychometric multidimensionality refers to additional sources of true score variance depicting associations between the items and non-target constructs that, when forcefully ignored in CFA, lead to biased parameter estimates (Asparouhov, Muthén, \& Morin, 2015; Morin, Arens. \& Marsh, 2016).

A first source of construct-relevant psychometric multidimensionality is particularly relevant to the need satisfaction construct and refers to the assessment of coexisting global and specific constructs. For instance, in the current debate regarding whether need satisfaction is best represented as a single global construct (Gillet, Fouquereau, Forest, Brunault, \& Colombat, 2012) or as conceptually-distinct subscales (Trépanier, Fernet, \& Austin, 2013, 2016), a third option exists according to which need satisfaction might exist as a global entity reflecting commonalities among ratings of autonomy, competence, and relatedness needs satisfaction, which themselves may include specificity unexplained by this global entity. Huyghebaert et al.'s (2018) higher-order results support the idea that ratings of autonomy, competence, and relatedness needs satisfaction are conceptuallyrelated dimensions of an overarching global need satisfaction construct. However, one remaining question is whether sufficient specificity exists in the three needs (autonomy, competence, and relatedness) once the global construct is taken into account.

Psychometrically, two distinct approaches can be used to study this question. The most typical of these approaches relies on hierarchical models (e.g., Huyghebaert et al., 2018). In hierarchical models, ratings on specific indicators are used to define first-order factors (autonomy, competence, and relatedness), which are themselves used to define a higher-order factor (global need satisfaction). However, hierarchical models suffer from one important limitation: They rely on a stringent proportionality constraint according to which the ratio of variance explained by the global factor relative to that explained by the specific factors is forced to be exactly the same for all items associated with a specific first-order factor (Morin, Arens, \& Marsh, 2016). Bifactor models provide a more flexible alternative not constrained by this unrealistic proportionality constraint (Chen, West, \& Sousa, 2006). In a $f$-factor bifactor model, one Global (G) factor (psychological need satisfaction) and $f-1$ orthogonal Specific (S) factors (autonomy, competence, and relatedness needs satisfaction) are used to explain the covariance among a set of $n$ items. Bifactor models directly test the presence of a global unitary construct underlying the answers to all items (G-Factor) and whether this global construct co-exists with meaningful specificities (S-Factors) not explained by the G-Factor. Thus, bifactor models provide a way to simultaneously consider both the forest (i.e., the presence of a global level of need satisfaction) and the trees (i.e., the specificities associated with ratings of autonomy, competence, and relatedness needs satisfaction) (Tóth-Király, Morin, Bőthe, Orosz, \& Rigó, 2018).

A second source of construct-relevant psychometric multidimensionality likely to be present in measures of need satisfaction occurs when items designed to assess one specific construct present some degree of true score association with non-target constructs (Morin, Arens, \& Marsh, 2016; Morin, Arens, Tran, \& Caci, 2016). For instance, workers' levels of autonomy need satisfaction may influence responses to items designed to assess their levels of competence or relatedness needs satisfaction due in part to the naturally imperfect nature of these ratings, but also to the fact that need satisfaction dimensions are interrelated conceptually (Bidee et al., 2017; Gillet, Lafrenière, Vallerand, Huart, \& Fouquereau, 2014). This form of construct-relevant multidimensionality calls for exploratory 
factor analyses (EFA) allowing for the free estimation of cross-loadings between items and conceptually-related constructs. EFA has recently been integrated with CFA and structural equation modeling into the exploratory structural equation modeling (ESEM) framework (Morin, Marsh, \& Nagengast, 2013), making it possible to consider that items tend to present at least some degree of valid association with more than one conceptually-related construct (Morin, Arens, \& Marsh, 2016; Morin, Arens, Tran, \& Caci, 2016). In particular, statistical research evidence (for a review, see Asparouhov et al., 2015) shows that excluding cross-loadings even as small as .100 tends to result in inflated estimates of the G-factor in bifactor-CFA or of factor correlations in CFA, whereas incorporating unnecessary cross-loadings has been shown not to result in estimation biases.

When we focus on the needs for autonomy, competence and relatedness or on closely related constructs, emerging research tends to support the value of a bifactor-CFA approach, but without systematically considering bifactor-ESEM solutions. Thus, in the sport area, Brunet, Gunnell, Teixeira, Sabiston, and Bélanger (2016) supported a bifactor-CFA representation of participants' satisfaction of their needs for competence, autonomy, and relatedness. Gillet et al. (2018) reported similar results in the educational area, while Bidee, Vantilborgh, Pepermans, Griep, and Hofmans' (2016) results also supported this approach in the work area. Fewer studies have considered the more comprehensive bifactor-ESEM framework. Thus, in the sport area, Myers, Martin, Ntoumanis, Celimli, and Bartholomew (2014) demonstrated the usefulness of a bifactor-ESEM approach when considering participants' levels of need thwarting. In a more comprehensive study focusing on ratings of global (rather than domain-specific) levels of need fulfillment (combining ratings of need satisfaction and frustration), Tóth-Király et al. (2018) similarly showed the value of a bifactor-ESEM approach in a series of two independent studies. To our knowledge, a single study (Sánchez-Oliva et al., 2017) has tested, and supported the added value, of a bifactor-ESEM representation of employees' ratings of their need satisfaction at work.

\section{Measurement Models: Estimation}

All measurement models were estimated using Mplus 8 (Muthén \& Muthén, 2017) robust Maximum Likelihood (MLR) estimator, which provides parameter estimates, standard errors, and goodness-of-fit that are robust to the non-normality of the response scales used in the present study (Finney \& DiStefano, 2013). These models were estimated with Full Information Maximum Likelihood (FIML; Enders, 2010) to handle the few missing responses present at the item level (Sample 1: 0\%; Sample 2: $0.00-1.62 \%)$.

CFA, bifactor-CFA, ESEM, and bifactor-ESEM representations of participants' ratings of need satisfaction at work were separately estimated in each sample following Morin et al.'s (Morin, Arens, \& Marsh, 2016; Morin, Boudrias et al., 2016, 2017) recommendations. In CFA, each item was only allowed to load on the factor it was assumed to measure and no cross-loadings were allowed. This model included three correlated factors representing autonomy, competence, and relatedness. In ESEM, the same set of three factors was represented using a confirmatory oblique target rotation (Browne, 2001). Target rotation makes it possible to freely estimate all main loadings while constraining all cross-loadings to be as close to zero as possible. In bifactor-CFA, all items were allowed to simultaneously load on one G-factor reflecting global levels of need satisfaction, and on three S-factors corresponding to specific levels of autonomy, competence, and relatedness. No crossloadings were allowed between the S-factors, and all factors were specified as orthogonal in line with bifactor assumptions (e.g., Morin, Arens, \& Marsh, 2016). Bifactor-ESEM estimated the same G- and $\mathrm{S}$-factors as the bifactor-CFA solution, allowing for the free estimation of cross-loadings between the S-factors using an orthogonal bifactor target rotation (Reise, Moore, \& Maydeu-Olivares, 2011).

Given the oversensitivity of the chi-square test to sample size and minor misspecifications (Marsh, Hau, \& Grayson, 2005), we relied on goodness-of-fit indices to describe the fit of the models: The comparative fit index (CFI), the Tucker-Lewis index (TLI), and the root mean square error of approximation (RMSEA) with its $90 \%$ confidence interval. According to typical interpretation guidelines (e.g., Marsh et al., 2005), values greater than .90 and .95 for the CFI and TLI respectively are considered to be indicative of adequate and excellent fit to the data, while values smaller than .08 or .06 for the RMSEA respectively support acceptable and excellent model fit. In the comparison of nested models (such as in tests of measurement invariance), typical guidelines suggest that models differing from one another by less than .01 on the CFI and TLI, or .015 on the RMSEA, can be considered to provide an equivalent level of fit to the data (Cheung \& Rensvold, 2002). 
As noted by Morin and colleagues (Morin, Arens, \& Marsh, 2016; Morin, Boudrias et al., 2016, 2017), fit indices are not sufficient to guide the selection of the optimal model. Indeed, each of these alternative models is able to absorb sources of construct-relevant multidimensionality left unmodelled, thus hiding sources of misfit behind apparently similarly fitting models (e.g., Asparouhov et al., 2015; Morin, Arens, \& Marsh, 2016). Unmodelled cross-loadings tend to result in inflated factor correlations in CFA, or inflated Gfactor loadings in bifactor-CFA. Likewise, an unmodelled G-factor tends to produce inflated factor correlations in CFA, or inflated cross-loadings in ESEM. Thus, an examination of parameter estimates and theoretical conformity is required to select the best alternative. As suggested by Morin and colleagues (Morin, Arens, \& Marsh, 2016; Morin, Boudrias et al., 2016, 2017), model comparison should always start by contrasting CFA and ESEM solutions. Here, statistical evidence shows that ESEM provides more exact estimates of factor correlations when cross-loadings are present in the population model while remaining unbiased otherwise (Asparouhov et al., 2015). For this reason, and as long as the factors remain welldefined, the observation of a distinct pattern of factor correlations should be taken as support for the ESEM solution. The second step involves contrasting the retained CFA or ESEM solution with a bifactor alternative. Here, the key elements supporting a bifactor model are the observation of: (1) an improved level of fit to the data; (2) a well-defined G-factor; and (3) at least some reasonably well-defined S-factors. The observation of multiple cross-loadings higher than .100 or .200 in ESEM that are reduced in bifactorESEM represents an additional source of evidence in favor of the bifactor solution (Morin, Arens, \& Marsh, 2016; Morin, Arens, Tran, \& Caci, 2016). For all models, we thus report standardized parameter estimates, and composite reliability coefficients associated with each of the a priori factors are calculated from the model standardized parameters using McDonald (1970) omega $(\omega)$ :

$$
\omega=\frac{\left(\sum\left|\lambda_{i}\right|\right)^{2}}{\left[\left(\sum\left|\lambda_{i}\right|\right)^{2}+\sum \delta_{i}\right]}
$$

where $\left|\lambda_{i}\right|$ are the standardized factor loadings in absolute values, and $\delta i$, the item uniquenesses.

\section{Measurement Models: Results}

Table S1 presents the goodness-of-fit indices of the measurement models estimated in both samples. Parameter estimates for all solutions obtained in Sample 1 are reported in Table S2, whereas those obtained in Sample 2 are reported in Table S3 of the online supplements. The CFA model failed to achieve an acceptable level of fit in both samples according to the TLI, as well as to the CFI and RMSEA in Sample 2. Both the bifactor-CFA and ESEM models achieved an acceptable, and comparable, level of fit in both samples according to all goodness-of-fit indices. Finally, the bifactorESEM model achieved an excellent level of fit to the data in both samples according to all goodnessof-fit indices, and a substantial increase in model fit relative to both the bifactor-CFA (Sample 1: $\triangle \mathrm{CFI}$ $=+.024 ; \Delta \mathrm{TLI}=+.018 ; \Delta \mathrm{RMSEA}=-.009 ;$ Sample $2: \Delta \mathrm{CFI}=+.033 ; \Delta \mathrm{TLI}=+.032 ; \Delta \mathrm{RMSEA}=-$ .015 ) and ESEM (Sample 1: $\Delta \mathrm{CFI}=+.027$; $\Delta \mathrm{TLI}=+.036 ; \Delta \mathrm{RMSEA}=-.016$; Sample 2: $\Delta \mathrm{CFI}=$ $+.018 ; \Delta \mathrm{TLI}=+.021 ; \triangle \mathrm{RMSEA}=-.010)$ results in both samples. Based on this statistical information, the bifactor-ESEM solution should be retained. However, as noted above, model selection needs to be based on a complete examination of the parameter estimates and theoretical conformity. Thus, we first compare the CFA and ESEM solutions, before comparing the ESEM and bifactor-ESEM solutions.

ESEM versus CFA. Parameter estimates for the CFA and ESEM solutions are very similar in Samples 1 and 2, and reveal factors that are well-defined by strong factor loadings and satisfactory estimates of composite reliability in Samples 1 (CFA: $\lambda=.602$ to $.895, M_{\lambda}=.740, \omega=.839$ to .888 ; ESEM: $\lambda=.310$ to $.994, M_{\lambda}=.680, \omega=.822$ to .875 ) and 2 (CFA: $\lambda=.503$ to $.849, M_{\lambda}=.746, \omega=$ .829 to .893 ; ESEM: $\lambda=.469$ to $.985, M_{\lambda}=.711, \omega=.819$ to .889$)$. When we look more carefully at the ESEM solution, despite the fact that multiple cross-loadings are small and non-statistically significant (17 out of 30 possible cross loadings in both samples), multiple cross-loadings remain relatively strong ( 8 cross-loadings are between .100 and .200 in Sample 1 and 7 in Sample 2, and 3 cross-loadings are higher than .200 in Sample 1 and 2 in Sample 2). Although the presence of crossloadings reinforces the need to incorporate this source of construct-relevant psychometric multidimensionality to the model, they also suggest that a global factor might be needed. Examination of the factor correlations associated with both of these solutions (see Table S4 of the online supplements) similarly reinforce the need to incorporate cross-loadings to the model, as these are somewhat reduced smaller in ESEM (Sample 1: $r=.586$ to .690 ; Sample 2: $r=.568$ to .605 ) relative to CFA (Sample 1: $r=.564$ to .618 ; Sample 2: $r=.529$ to .575 ) in both samples.

ESEM versus Bifactor-ESEM. The bifactor-ESEM results reveal a G-Factor well-defined by 
strong and positive loadings from most items in both samples (Sample 1: $\lambda=.451$ to $.788 ; M_{\lambda}=.621$, $\omega=.937$; Sample 2: $\lambda=.264$ to $\left..798 ; M_{\lambda}=.578, \omega=.929\right)$. Over and above this G-Factor, most items associated with the relatedness (Sample 1: $\lambda=.381$ to $.619 ; M_{\lambda}=.465, \omega=.696$; Sample 2: $\lambda=.514$ to $.622 ; M_{\lambda}=.487, \omega=.711$ ) and competence (Sample 1: $\lambda=.169$ to $.677, M_{\lambda}=.438, \omega=.703$; Sample $2: \lambda=.337$ to $\left..712, M_{\lambda}=.502, \omega=.758\right) \mathrm{S}$-factors retain a satisfactory level of specificity. In contrast, the autonomy S-factor appears to be more weakly defined by a majority of items (Sample 1: $\lambda=.006$ to $.607, M_{\lambda}=.292$; Sample $2: \lambda=.093$ to $.855, M_{\lambda}=.413$ ), suggesting that autonomy ratings mainly define participants' global levels of need satisfaction. Still, the fact that this S-Factor retains less specificity than the other S-factors does not signify that this specificity is not meaningful, especially when models using an approach that explicitly controls for measurement errors and associations with the global need satisfaction construct. Indeed, this S-factor appears to retain at least some amount of specificity as illustrated by non-negligible estimates of composite reliability (Sample 1: $\omega=.595$; Sample 2: $\omega=.760$ ). Finally, the superiority of the bifactor-ESEM solution is also apparent from the observation of reduced cross-loadings (no cross-loadings higher than .200 remain in the solution, and 7 cross-loadings between .100 and .200 remain in Sample 1 and 5 in Sample 2).

Measurement Invariance. The bifactor-ESEM solution was retained in both samples and used for tests of measurement invariance. However, in order to be able to compare LPA solutions estimated based on first-order, relative to bifactor, factor scores, we also retained the ESEM solution. These tests were conducted in the following sequence (Millsap, 2011): (a) configural invariance, (b) weak invariance (loadings), (c) strong invariance (loadings, intercepts), (d) strict invariance (loadings, intercepts, uniquenesses), (e) invariance of the latent variances-covariances (loadings, intercepts, uniquenesses, variances-covariances), and (f) latent means invariance (loadings, intercepts, uniquenesses, variancescovariances, latent means). The results from the tests of measurement invariance realized on these two solutions are reported in the bottom of Table S1, and support the complete measurement invariance of both solutions (i.e., none of the changes in fit indices exceeded the recommended guidelines). Factors scores for the person-centered analyses were extracted from the model of complete measurement invariance for both solutions. Although only strict measurement invariance is required to ensure that measurement of the constructs remains equivalent across samples for models based on factor scores (Millsap, 2011), there are advantages to saving factors scores from a model of complete measurement invariance, which provides measures which are directly comparable across samples based on a mean of 0 and a SD of 1 .

\section{References used in these Supplements}

Asparouhov, T., Muthén, B., \& Morin, A.J.S. (2015). Bayesian structural equation modeling with cross-loadings and residual covariances. Journal of Management, 41, 1561-1577.

Bidee, J., Vantilborgh, T., Pepermans, R., Griep, Y., \& Hofmans, J. (2016). Temporal dynamics of need satisfaction and need frustration. Two sides of the same coin? European Journal of Work and Organizational Psychology, 25, 900-913.

Bidee, J., Vantilborgh, T., Pepermans, R., Willems, J., Jegers, M., \& Hofmans, J. (2017). Daily motivation of volunteers in healthcare organizations: Relating team inclusion and intrinsic motivation using self-determination theory. European Journal of Work and Organizational Psychology, 26, 325-336.

Browne, M. (2001) An overview of analytic rotation in exploratory factor analysis. Multivariate Behavioral Research, 36, 111-150.

Brunet, J., Gunnell, K.E., Teixeira, P., Sabiston, C.M., \& Bélanger, M. (2016). Should we be looking at the forest or the trees? Overall psychological need satisfaction and individual needs as predictors of physical activity. Journal of Sport \& Exercise Psychology, 38, 317-330.

Chen, F.F., West, S.G., \& Sousa, K.H. (2006). A comparison of bifactor and second-order models of quality of life. Multivariate Behavioral Research, 41, 189-225.

Cheung, G.W., \& Rensvold, R.B. (2002). Evaluating goodness-of-fit indexes for testing measurement invariance. Structural Equation Modeling, 9, 233-255.

Enders, C. (2010). Applied missing data analysis. New York, NY: Guilford.

Finney, S.J., \& DiStefano, C. (2013). Non-normal and categorical data in structural equation modeling. In G.R. Hancock \& R.O. Mueller (Eds), Structural equation modeling: A second course ( $2^{\text {nd }}$ ed., pp. 439-492). Greenwich, CO: IAP.

Gillet, N., Fouquereau, E., Forest, J., Brunault, P., \& Colombat, P. (2012). The impact of 
organizational factors on psychological needs and their relations with well-being. Journal of Business and Psychology, 27, 437-450.

Gillet, N., Lafrenière, M.-A.K., Vallerand, R.J., Huart, I., \& Fouquereau, E. (2014). The effects of autonomous and controlled regulation of performance-approach goals on well-being: A process model. British Journal of Social Psychology, 53, 154-174.

Gillet, N., Morin, A., Huyghebaert, T., Burger, L., Maillot, A., Poulin, A., \& Tricard, E. (2018). University students' need satisfaction trajectories: A growth mixture analysis. Learning and Instruction. Early view. doi: 10.1016/j.learninstruc.2017.11.003

Huyghebaert, T., Gillet, N., Fernet, C., Lahiani, F.-J., Chevalier, S., \& Fouquereau, E. (2018). Investigating the longitudinal effects of surface acting on managers' functioning through psychological needs. Journal of Occupational Health Psychology, 23, 207-222.

Marsh, H.W., Hau, K.-T., \& Grayson, D. (2005). Goodness of fit evaluation in structural equation modeling. In A. Maydeu-Olivares \& J. McArdle (Eds.), Contemporary psychometrics. A Festschrift for Roderick P. McDonald. Mahwah, NJ: Erlbaum.

Marsh, H.W., Morin, A.J.S., Parker, P.D., \& Kaur, G. (2014). Exploratory structural equation modelling: An integration of the best features of exploratory and confirmatory factor analyses. Annual Review of Clinical Psychology, 10, 85-110.

McDonald, R. (1970). Theoretical foundations of principal factor analysis, canonical factor analysis, and alpha factor analysis. British Journal of Mathematical \& Statistical Psychology, 23, 1-21.

Millsap, R.E. (2011). Statistical approaches to measurement invariance. New York: Taylor \& Francis.

Morin, A.J.S., Arens, A., Tran, A., \& Caci, H. (2016). Exploring sources of construct-relevant multidimensionality in psychiatric measurement: A tutorial and illustration using the Composite Scale of Morningness. International Journal of Methods in Psychiatric Research, 25, 277-288.

Morin, A.J.S., Boudrias, J.-S., Marsh, H.W., Madore, I., \& Desrumeaux, P. (2016). Further reflections on disentengling shape and level effects in person-centered analyses: An illustration exploring the dimensionality of psychological health. Structural Equation Modeling, 23, 438-454.

Morin, A.J.S., Boudrias, J.-S., Marsh, H.W., McInerney, D.M., Dagenais-Desmarais, V., Madore, I., \& Litalien, D. (2017). Complementary variable- and person-centered approaches to the dimensionality of psychometric constructs: Application to psychological wellbeing at work. Journal of Business and Psychology, 32, 395-419.

Morin, A.J.S., Arens, A.K., \& Marsh, H. (2016). A bifactor exploratory structural equation modeling framework for the identification of distinct sources of construct-relevant psychometric multidimensionality. Structural Equation Modeling, 23, 116-139.

Morin, A.J.S., Marsh, H.W., \& Nagengast, B. (2013). Exploratory structural equation modeling. In G.R. Hancock \& R.O. Mueller (Eds.), Structural equation modeling: A second course ( $2^{\text {nd }}$ ed., pp. 395-436). Charlotte, NC: Information Age.

Myers, N.D., Martin, J.J., Ntoumanis, N., Celimli, S., \& Bartholomew, K.J. (2014). Exploratory bifactor analysis in sport, exercise, and performance psychology: A substantive-methodological synergy. Sport, Exercice, \& Performance Psychology, 3, 258-272.

Muthén, L.K., \& Muthén, B. (2017). Mplus user's guide. Los Angeles, CA: Muthén \& Muthén.

Reise, S.P., Moore, T.M., \& Maydeu-Olivares, A. (2011). Targeted bifactor rotations and assessing the impact of model violations on the parameters of unidimensional and bifactor models. Educational and Psychological Measurement, 71, 684-711.

Sánchez-Oliva, D., Morin, A.J.S., Teixeira, P.J., Carraça, E.V., Palmeira, A.L., \& Silva, M.N. (2017). A bifactor exploratory structural equation modeling representation of the structure of the Basic Psychological Needs at Work Scale. Journal of Vocational Behavior, 98, 173-187.

Tóth-Király, I., Morin, A.J.S., Bőthe, B., Orosz, G., \& Rigó, A. (2018). Investigating the multidimensionality of need fulfillment: A bifactor exploratory structural equation modeling representation. Structural Equation Modeling, 25, 267-286.

Trépanier, S.-G., Fernet, C., \& Austin, S. (2013). Workplace bullying and psychological health at work: The mediating role of satisfaction of needs for autonomy, competence and relatedness. Work \& Stress, 27, 123-140.

Trépanier, S.-G., Fernet, C., \& Austin, S. (2016). Longitudinal relationships between workplace bullying, basic psychological needs, and employee functioning: A simultaneous investigation of psychological need satisfaction and frustration. European Journal of Work and Organizational 
Online Supplements for Need Satisfaction Profiles S7

Psychology, 25, 690-706. 


\section{Class Enumeration Procedure and Tests of Profile Similarity}

To determine the optimal number of profiles, multiple sources of information need to be considered, including the substantive meaningfulness, theoretical conformity, and statistical adequacy of the solutions (Marsh et al., 2009; Morin, 2016; Muthén, 2003). In addition, statistical indices are available to support this decision (McLachlan \& Peel, 2000): (i) the Akaïe Information Criterion (AIC), (ii) the Consistent AIC (CAIC), (iii) the Bayesian Information Criterion (BIC), (iv) the sample-size Adjusted BIC (ABIC), (v) the standard and adjusted Lo, Mendell and Rubin's (2001) Likelihood Ratio Tests (LMR/aLMR; as these tests typically yield the same conclusions, we only report the aLMR), and (vi) the Bootstrap Likelihood Ratio Test (BLRT). A lower value on the AIC, CAIC, BIC, and ABIC suggests a better-fitting model. The aLMR and BLRT compare a $k$-class model with a $k$ - 1 -class model. A significant $p$ value indicates that the $k$ - 1 -class model should be rejected in favor of a $k$-class model.

Simulation studies indicate that four of these indicators (CAIC, BIC, ABIC, and BLRT) are particularly effective (Henson, Reise, \& Kim, 2007; Nylund, Asparouhov, \& Muthén, 2007; Peugh \& Fan, 2013; Tein, Coxe, \& Cham, 2013; Tofighi \& Enders, 2008), while the AIC and LMR/ALMR should not be used in the class enumeration process as they respectively tend to over- and underextract incorrect number of profiles (Diallo, Morin, \& Lu, 2016, 2017; Henson et al., 2007; Nylund et al., 2007; Peugh \& Fan, 2013; Tofighi \& Enders, 2008). These indicators will thus be reported only in order to ensure a complete disclosure, but will not be used to select the optimal number of profiles. It should be noted that these tests remain heavily influenced by sample size (Marsh et al., 2009), so that with sufficiently large samples, they may keep on suggesting the addition of profiles without reaching a minimum. In this situation, the point at which these indicators appear to reach a plateau can be used as an additional indicator to inform the selection of the optimal solution (Morin, Maïano et al., 2011). Finally, the entropy indicates the precision with which the cases are classified into the various profiles. The entropy should not be used to determine the optimal number of profiles (Lubke \& Muthén, 2007), but summarizes the classification accuracy ( 0 to 1$)$, with higher values indicating greater accuracy.

Once the optimal number of profiles has been selected in each sample, we integrated the two retained LPA solutions (one per sample) into a single multi-group LPA model allowing for systematic tests of profile similarity. These tests were conducted following the sequential strategy proposed by Morin, Meyer et al. (2016) for tests of profile similarity across multiple groups: (a) configural similarity (i.e., same number of profiles); (b) structural similarity (i.e., same within-profile mean levels on the profile indicators); (c) dispersion similarity (i.e., same within-profile variance of the profile indicators); and (d) distributional similarity (i.e., same relative size of the profiles). The fit of these models can be compared using the aforementioned information criteria. Morin, Meyer et al. (2016) also suggest that at least two indices out of the CAIC, BIC, and ABIC should be lower for the more "similar" model for the hypothesis of profile similarity to be supported.

The fit indices of the LPAs estimated from bifactor factor scores separately in both samples are reported in the top (Sample 1) and middle (Sample 2) sections of Table S9 of these online supplements, and the elbow plots associated with these results are presented in Figure S1 of the online supplements. Comparable results for models estimated based on first-order factor scores are reported in Table S10 and Figure S2 of the online supplements. In Sample 1, all indices kept on suggesting the addition of profiles. In Sample 2, the ABIC and BLRT kept on suggesting the addition of profiles, whereas the CAIC and BIC respectively supported 5 and 7 profiles. The elbow plots associated with these solutions attain a first point of inflexion after 3 profiles, although this inflexion point was not as marked in Sample 1. Based on these observations, we carefully examined solutions including 3 to 6 profiles in both samples. This examination showed that all solutions were fully proper statistically and characterized by a very high level of similarity across samples. Furthermore, this examination revealed that moving from 3 to 4 profiles resulted in the addition of a meaningfully different profile to the solution in both samples, whereas moving from 4 to 5 , or from 5 to 6 , profiles simply resulted in the arbitrary division of one profile into very small $(\leq 1 \%)$ and similar profiles. The 4-profile solution was thus retained in both samples, supporting its configural similarity. For comparison purposes, the 4profile solution was also retained for models based on first-order factor scores.

A multigroup LPA of configural similarity, including 4 profiles per sample, was then estimated. The fit indices from all multigroup LPAs are reported in the bottom section of Table S9, and support the structural similarity of the profiles across samples based on the observation of reduced CAIC, $\mathrm{BIC}$, and $\mathrm{ABIC}$ value associated with this solution, but not the dispersion similarity of the profiles as 
this model results in higher values on all information criteria. A careful examination of the results revealed that scores on the relatedness S-factors presented slightly higher within-profile variability in Sample 2 (suggesting that profiles estimated in Sample 2 were slightly less "homogenous" in terms of relatedness than those estimated in Sample 1). We thus estimated an additional model of partial dispersion similarity in which equality constraints across samples were relaxed on the variances of the relatedness S-factor. Relative to the model of configural similarity, this model resulted in lower values on the CAIC and BIC, supporting the partial dispersion similarity of this solution across samples. Finally, we estimated a model of distributional similarity by constraining the size of the latent profiles to be equal across samples. Compared with the model of partial dispersion similarity, this model resulted in lower values on the CAIC, BIC, and ABIC, thereby supporting the distributional similarity of the solution. Comparable results for the models based on first-order factors scores are reported in Table S10 of the online supplements, and converge on identical conclusions.

\section{References used in these Supplements}

Diallo, T.M.O, Morin, A.J.S., \& Lu, H. (2016). Impact of misspecifications of the latent variancecovariance and residual matrices on the class enumeration accuracy of growth mixture models. Structural Equation Modeling, 23, 507-531.

Diallo, T.M.O, Morin, A.J.S., \& Lu, H. (2017). The impact of total and partial inclusion or exclusion of active and inactive time invariant covariates in growth mixture models. Psychological Methods, 22, 166-190.

Henson, J.M., Reise, S.P., \& Kim, K.H. (2007). Detecting mixtures from structural model differences using latent variable mixture modeling: A comparison of relative model fit statistics. Structural Equation Modeling, 14, 202-226.

Lo, Y., Mendell, N., \& Rubin, D. (2001). Testing the number of components in a normal mixture. Biometrika, 88, 767-778.

Lubke, G.H., \& Muthén, B.O. (2005). Investigating population heterogeneity with factor mixture models. Psychological Methods, 10, 21-39.

Marsh, H.W., Lüdtke, O., Trautwein, U., \& Morin, A.J.S. (2009). Classical latent profile analysis of academic self-concept dimensions: Synergy of person- and variable-centered approaches to theoretical models of self-concept. Structural Equation Modeling, 16, 191-225.

McLachlan, G., \& Peel, D. (2000). Finite mixture models. New York, NY: Wiley.

Morin, A.J.S. (2016). Person-centered research strategies in commitment research. In J.P. Meyer (Ed.), The handbook of employee commitment (p. 490-508). Cheltenham: Edward Elgar.

Morin, A.J.S., Maïano, C., Nagengast, B., Marsh, H.W., Morizot, J., \& Janosz, M. (2011). Growth mixture modeling of adolescents trajectories of anxiety: The impact of untested invariance assumptions on substantive interpretations. Structural Equation Modeling, 18, 613-648.

Morin, A.J.S., Meyer, J.P., Creusier, J., \& Biétry, F. (2016). Multiple-group analysis of similarity in latent profile solutions. Organizational Research Methods, 19, 231-254.

Muthén, B.O. (2003). Statistical and substantive checking in growth mixture modeling: Comment on Bauer and Curran (2003). Psychological Methods, 8, 369-377.

Nylund, K.L., Asparouhov, T., \& Muthén, B. (2007). Deciding on the number of classes in latent class analysis and growth mixture modeling. Structural Equation Modeling, 14, 535-569.

Peugh, J., \& Fan, X. (2013). Modeling unobserved heterogeneity using latent profile analysis: A Monte Carlo simulation. Structural Equation Modeling, 20, 616-639.

Tein, J.-Y., Coxe, S., \& Cham, H. (2013). Statistical power to detect the correct number of classes in latent profile analysis. Structural Equation Modeling, 20, 640-657.

Tofighi, D., \& Enders, C. (2008). Identifying the correct number of classes in growth mixture models. In G.R. Hancock \& K.M. Samuelsen (Eds.), Advances in latent variable mixture models (pp. 317-341). Charlotte, NC: Information Age. 


\section{Table S1}

Goodness-of-Fit Statistics of the Alternative Measurement Models

\begin{tabular}{|c|c|c|c|c|c|c|c|c|c|c|}
\hline Description & $\chi^{2}(d f)$ & CFI & TLI & RMSEA & $90 \% \mathrm{CI}$ & $\Delta \chi^{2}$ & $\Delta d f$ & $\Delta \mathrm{CFI}$ & $\Delta \mathrm{TLI}$ & $\triangle$ RMSEA \\
\hline \multicolumn{11}{|l|}{ Sample 1} \\
\hline CFA & $979.760(87)^{*}$ & .879 & .854 & .085 & {$[.080 ; .090]$} & - & & - & - & - \\
\hline ESEM & $429.566(63)^{*}$ & .950 & .917 & .064 & {$[.058 ; .070]$} & - & & - & - & - \\
\hline B-CFA & $417.993(75)^{*}$ & .953 & .935 & .057 & {$[.052 ; .062]$} & - & & - & - & - \\
\hline B-ESEM & $220.066(51)^{*}$ & .977 & .953 & .048 & {$[.042 ; .055]$} & - & & - & - & - \\
\hline \multicolumn{11}{|l|}{ Sample 2} \\
\hline CFA & $433.125(87)^{*}$ & .907 & .887 & .077 & {$[.070 ; .084]$} & - & & - & - & - \\
\hline ESEM & $217.273(63) *$ & .958 & .931 & .060 & {$[.052 ; .069]$} & - & & - & - & - \\
\hline B-CFA & $288.387(75)^{*}$ & .943 & .920 & .065 & {$[.057 ; .073]$} & - & & - & - & - \\
\hline B-ESEM & $138.295(51)^{*}$ & .976 & .952 & .050 & {$[.040 ; .060]$} & - & & - & - & - \\
\hline \multicolumn{11}{|l|}{ Measurement Invariance (ESEM) } \\
\hline Configural invariance & $653.437(126)^{*}$ & .953 & .922 & .063 & {$[.058 ; .068]$} & - & & - & - & - \\
\hline Weak invariance & $736.488(162)^{*}$ & .949 & .934 & .058 & {$[.054 ; .062]$} & $86.476^{*}$ & 36 & -.004 & +.012 & -.005 \\
\hline Strong invariance & $816.271(174)^{*}$ & .943 & .931 & .059 & {$[.055 ; .063]$} & $89.543^{*}$ & 12 & -.006 & -.003 & +.001 \\
\hline Strict invariance & $889.155(189)^{*}$ & .938 & .931 & .059 & {$[.056 ; .063]$} & $72.190 *$ & 15 & -.005 & .000 & .000 \\
\hline Latent variance-covariance invariance & $904.863(195)^{*}$ & 937 & .932 & .059 & {$[.055 ; .063]$} & 16.558 & 6 & -.001 & +.001 & .000 \\
\hline Latent means invariance & $921.547(198)^{*}$ & .936 & .932 & .059 & {$[.055 ; .063]$} & $17.680 *$ & 3 & -.001 & .000 & .000 \\
\hline \multicolumn{11}{|l|}{ Measurement Invariance (Bifactor-ESEM) } \\
\hline Configural invariance & $365.506(102)^{*}$ & .977 & .952 & .050 & {$[.044 ; .055]$} & - & & - & - & - \\
\hline Weak invariance & $437.711(146)^{*}$ & .974 & .963 & .044 & {$[.039 ; .048]$} & $85.549 *$ & 44 & -.003 & +.011 & -.006 \\
\hline Strong invariance & $513.819(157)^{*}$ & .968 & .958 & .047 & {$[.042 ; .051]$} & $93.742 *$ & 11 & -.006 & -.005 & +.003 \\
\hline Strict invariance & $624.997(172)^{*}$ & .960 & .951 & .050 & {$[.046 ; .054]$} & $109.213 *$ & 15 & -.008 & -.007 & +.003 \\
\hline Latent variance-covariance invariance & $626.248(182)^{*}$ & .961 & .954 & .048 & {$[.044 ; .052]$} & 14.659 & 10 & +.001 & +.003 & -.002 \\
\hline Latent means invariance & $644.032(186)^{*}$ & .959 & .954 & .048 & {$[.044 ; .053]$} & $18.856^{*}$ & 4 & -.002 & .000 & .000 \\
\hline
\end{tabular}

Note. ${ }^{*} p<.01 ; \chi^{2}$ : robust chi-square test of exact fit; $d f$ : degrees of freedom; CFI: comparative fit index; TLI: Tucker-Lewis index; RMSEA: root mean

square error of approximation; $90 \% \mathrm{CI}$ : $90 \%$ confidence interval; $\Delta$ : change in fit relative to the preceding model in the sequence. 
Table S2

Standardized Factor Loadings ( $\lambda$ ) and Uniquenesses $(\delta)$ in Sample 1

\begin{tabular}{|c|c|c|c|c|c|c|c|c|c|c|c|c|c|c|}
\hline & CFA & & B-CFA & & & ESEM & & & & ESEN & & & & \\
\hline Items & $\lambda$ & $\delta$ & $\mathrm{G}-\lambda$ & $S-\lambda$ & $\delta$ & $\Lambda$ & $\lambda$ & $\lambda$ & $\delta$ & $\mathrm{G}-\lambda$ & $S-\lambda$ & $S-\lambda$ & $S-\lambda$ & $\delta$ \\
\hline \multicolumn{15}{|l|}{ Autonomy } \\
\hline Item 1 & .654 & .572 & .697 & .068 & .510 & .505 & .039 & .172 & .584 & .741 & .006 & -.131 & -.123 & .418 \\
\hline Item 2 & .686 & .530 & .778 & -.002 & .394 & .423 & .103 & .300 & .485 & .788 & -.009 & -.056 & .016 & .375 \\
\hline Item 3 & .813 & .340 & .776 & .252 & .335 & .701 & .078 & .071 & .368 & .780 & .243 & -.035 & -.081 & .324 \\
\hline Item 4 & .850 & .277 & .650 & .624 & .187 & .940 & .023 & -.150 & .231 & .649 & .607 & .037 & -.047 & .207 \\
\hline Item 5 & .895 & .199 & .725 & .575 & .144 & .989 & -.016 & -.096 & .137 & .720 & .596 & -.005 & -.041 & .126 \\
\hline$\omega$ & .888 & & & .596 & & .875 & & & & & .595 & & & \\
\hline \multicolumn{15}{|l|}{ Competence } \\
\hline Item 1 & .780 & .391 & .525 & .661 & .288 & -.114 & .921 & -.040 & .305 & .551 & -.054 & .620 & .053 & .307 \\
\hline Item 2 & .788 & .410 & .645 & .378 & .441 & .049 & .588 & .184 & .439 & .648 & -.052 & .366 & .112 & .432 \\
\hline Item 3 & .763 & .608 & .493 & .339 & .642 & .090 & .485 & .089 & .633 & .469 & .093 & .357 & .143 & .624 \\
\hline Item 4 & .602 & .504 & .749 & .149 & .417 & .406 & .310 & .143 & .445 & .715 & .140 & .169 & .050 & .439 \\
\hline Item 5 & .703 & .350 & .552 & .676 & .238 & -.046 & .994 & -.152 & .222 & .568 & .009 & .677 & -.003 & .219 \\
\hline$\omega$ & .854 & & & .705 & & & .842 & & & & & .703 & & \\
\hline \multicolumn{15}{|l|}{ Relatedness } \\
\hline Item 1 & .706 & .501 & .571 & .425 & .494 & .085 & -.037 & .696 & .475 & .598 & -.076 & -.042 & .396 & .478 \\
\hline Item 2 & .788 & .379 & .535 & .630 & .317 & -.045 & -.049 & .868 & .336 & .551 & -.064 & .008 & .619 & .309 \\
\hline Item 3 & .763 & .418 & .540 & .527 & .430 & -.020 & .114 & .679 & .448 & .534 & .005 & .131 & .525 & .422 \\
\hline Item 4 & .602 & .638 & .448 & .391 & .646 & .061 & -.019 & .569 & .649 & .451 & -.003 & .010 & .381 & .652 \\
\hline Item 5 & .703 & .505 & .561 & .400 & .526 & .018 & .207 & .538 & .515 & .546 & -.002 & .173 & .406 & .507 \\
\hline$\omega$ & .839 & & .934 & .700 & & & & .822 & & .937 & & & .696 & \\
\hline
\end{tabular}

Note: CFA: confirmatory factor analysis; ESEM: exploratory factor analyses; G: global factor estimated as part of a bifactor model; S: specific factor estimated as part of a bifactor model; $\lambda$ : factor loading; $\delta$ : item uniqueness; $\omega$ : omega coefficient of model-based composite reliability; target ESEM and BESEM factor loadings are indicated in bold; non-significant parameters $(p \geq .05)$ are marked in italics. 


\section{Table S3}

Standardized Factor Loadings ( $\lambda$ ) and Uniquenesses $(\delta)$ in Sample 2

\begin{tabular}{|c|c|c|c|c|c|c|c|c|c|c|c|c|c|c|}
\hline & CFA & & B-CFA & & & ESEM & & & & B-ESEN & & & & \\
\hline Items & $\lambda$ & $\delta$ & $\mathrm{G}-\lambda$ & $S-\lambda$ & $\delta$ & $\lambda$ & $\lambda$ & $\lambda$ & $\delta$ & $\mathrm{G}-\lambda$ & $S-\lambda$ & $S-\lambda$ & $S-\lambda$ & $\delta$ \\
\hline \multicolumn{15}{|l|}{ Autonomy } \\
\hline Item 1 & .793 & .371 & 670 & .376 & .409 & .720 & .030 & .059 & .409 & .721 & .313 & -.077 & -.070 & .372 \\
\hline Item 2 & .714 & .491 & .767 & .115 & .399 & .501 & .119 & .218 & .478 & .765 & .093 & -.041 & .008 & .404 \\
\hline Item 3 & .840 & .295 & .731 & .368 & .330 & .765 & .102 & -.011 & .332 & .798 & .286 & -.066 & -.163 & .250 \\
\hline Item 4 & .755 & .429 & .502 & .689 & .273 & .879 & -.079 & -.077 & .354 & .464 & .855 & .046 & .077 & .046 \\
\hline Item 5 & .849 & .280 & .658 & .594 & .213 & .914 & -.036 & -.024 & .219 & .677 & .517 & -.039 & -.027 & .272 \\
\hline$\omega$ & .893 & & & .739 & & .889 & & & & & .760 & & & \\
\hline \multicolumn{15}{|l|}{ Competence } \\
\hline Item 1 & .795 & .367 & .533 & .610 & .343 & -.059 & $\mathbf{8 3 7}$ & .001 & .347 & .537 & -.029 & .597 & .056 & .352 \\
\hline Item 2 & .824 & .321 & .617 & .517 & .352 & -.021 & .763 & .094 & .345 & .616 & -.084 & .516 & .076 & .342 \\
\hline Item 3 & .610 & .628 & .521 & .302 & .637 & .046 & .469 & .163 & .633 & .471 & .031 & .349 & .155 & .631 \\
\hline Item 4 & .699 & .511 & .667 & .285 & .474 & .338 & .494 & .004 & .461 & .623 & .169 & .337 & .024 & .469 \\
\hline Item 5 & .819 & .329 & .505 & .727 & .217 & -.086 & .985 & -.128 & .229 & .519 & -.050 & .712 & -.015 & .221 \\
\hline$\omega$ & .867 & & & .747 & & & .862 & & & & & .758 & & \\
\hline \multicolumn{15}{|l|}{ Relatedness } \\
\hline Item 1 & .730 & .468 & .493 & .564 & .439 & .028 & -.110 & .786 & .448 & .518 & -.024 & -.057 & .532 & .445 \\
\hline Item 2 & .843 & .290 & .590 & .628 & .258 & -.035 & -.068 & .940 & .215 & .615 & -.082 & -.023 & .622 & .227 \\
\hline Item 3 & .699 & .512 & .556 & .403 & .529 & .045 & .177 & .544 & .526 & .532 & .006 & .166 & .415 & .517 \\
\hline Item 4 & .503 & .746 & .279 & .438 & .731 & -.013 & .001 & .486 & .770 & .264 & .086 & .098 & .439 & .721 \\
\hline Item 5 & .714 & .490 & .570 & .410 & .507 & .056 & .143 & .581 & .501 & .551 & .019 & .135 & .425 & .497 \\
\hline$\omega$ & .829 & & .925 & .708 & & & & .819 & & .929 & & & .711 & \\
\hline
\end{tabular}

Note: CFA: Confirmatory factor analysis; ESEM: exploratory factor analyses; G: global factor estimated as part of a bifactor model; S: specific factor estimated as part of a bifactor model; $\lambda$ : factor loading; $\delta$ : item uniqueness; $\omega$ : omega coefficient of model-based composite reliability; Target ESEM and BESEM factor loadings are indicated in bold; Non-significant parameters $(p \geq .05)$ are marked in italics. 
Table S4

Latent Factor Correlations for the CFA and ESEM Solutions

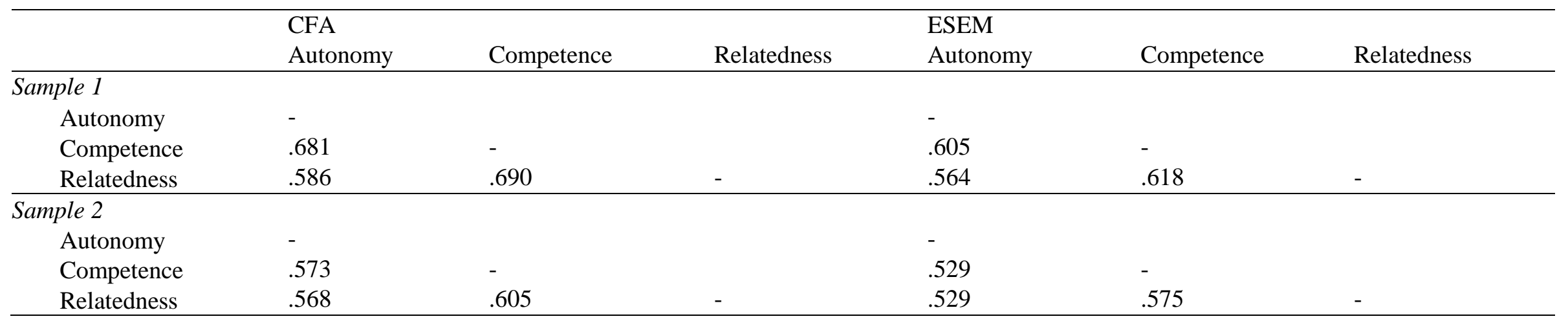

Note. CFA: confirmatory factor analysis; ESEM: exploratory structural equation modeling; All correlations are statistically significant $(p<.01)$ 


\section{Table S5}

Standardized Factor Loadings ( $\lambda$ ), Uniquenesses ( $\delta$ ), and Latent Correlations for the Predictors (Sample 1)

\begin{tabular}{|c|c|c|c|c|c|c|c|c|c|c|c|c|}
\hline & Mental Load & & Workload & & Information & & Participation & & Colleagues Support & & Role Ambiguity & \\
\hline Items & $\lambda$ & $\delta$ & $\lambda$ & $\delta$ & $\lambda$ & $\delta$ & $\lambda$ & $\delta$ & $\lambda$ & $\delta$ & $\lambda$ & $\delta$ \\
\hline Item 1 & .791 & .375 & .765 & .414 & .647 & .582 & .853 & .272 & .794 & .370 & .816 & .334 \\
\hline Item 2 & .745 & .445 & .839 & .297 & .880 & .226 & .876 & .233 & .903 & .185 & .802 & .356 \\
\hline Item 3 & .775 & .399 & .757 & .427 & .849 & .280 & .843 & .290 & .793 & .370 & .712 & .493 \\
\hline Item 4 & .855 & .270 & .707 & .500 & .700 & .511 & .685 & .530 & .890 & .208 & .572 & .673 \\
\hline$\omega$ & .871 & & .852 & & .855 & & .889 & & .910 & & .819 & \\
\hline \multicolumn{2}{|c|}{ Correlations } & 1 & 2 & 3 & 4 & 5 & 6 & & & & & \\
\hline \multicolumn{2}{|c|}{ 1. Mental Load } & -- & & & & & & & & & & \\
\hline \multicolumn{2}{|c|}{ 2. Workload } & .565 & -- & & & & & & & & & \\
\hline \multicolumn{2}{|c|}{ 3. Information } & .244 & .058 & -- & & & & & & & & \\
\hline \multicolumn{2}{|c|}{ 4. Participation } & .199 & .136 & .643 & -- & & & & & & & \\
\hline \multicolumn{2}{|c|}{ 5. Colleagues Support } & .181 & -.037 & .329 & .264 & -- & & & & & & \\
\hline \multicolumn{2}{|c|}{ 6. Role Ambiguity } & -.295 & .037 & -.563 & -.461 & -.485 & -- & & & & & \\
\hline
\end{tabular}

Note: $\lambda$ : factor loading; $\delta$ : item uniqueness; Non-significant parameters $(p \geq .05)$ are marked in italics 
Table S6

Standardized Factor Loadings ( $\lambda$ ), Uniquenesses ( $\delta$ ), and Latent Correlations for the Predictors and Outcomes (Sample 2)

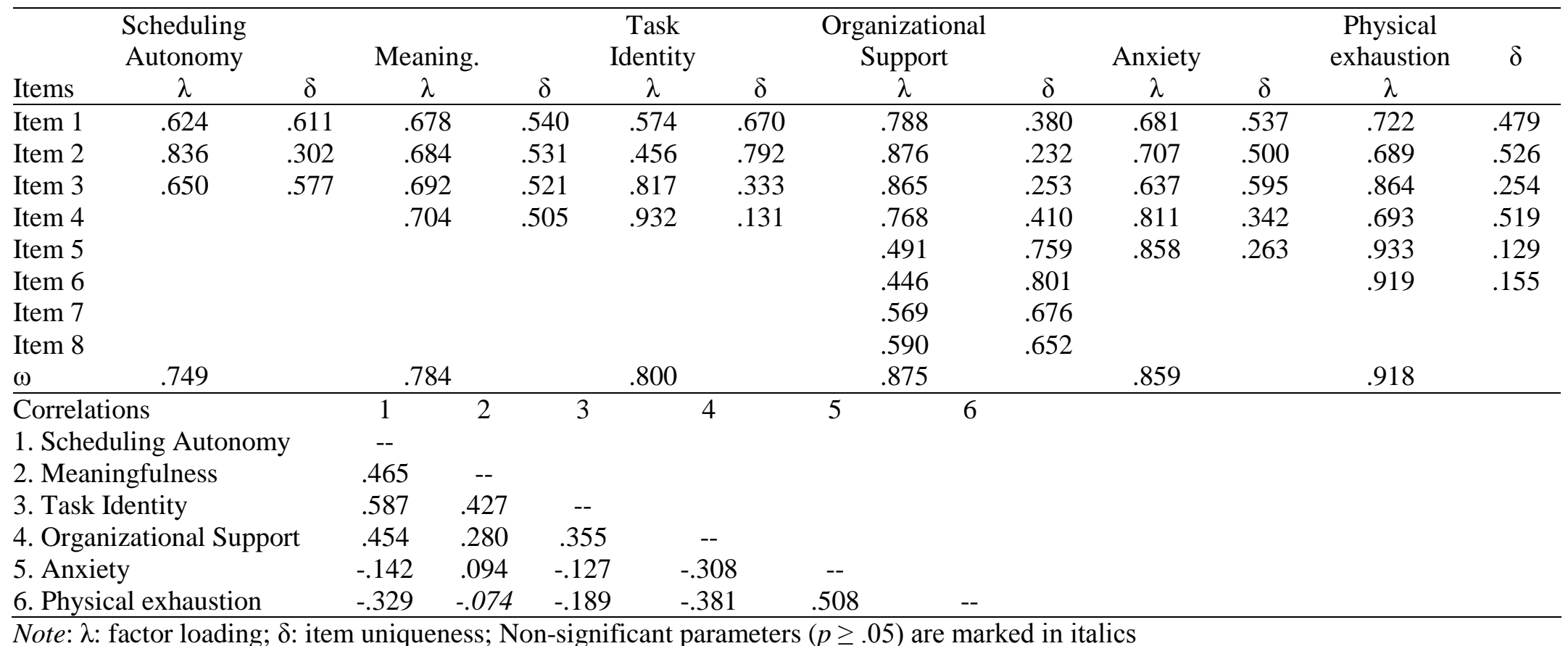

Note: $\lambda$ : factor loading; $\delta$ : item uniqueness; Non-significant parameters $(p \geq .05)$ are marked in italics 
Table S7

Correlations between Variables (Sample 1)

1.20

3.

4.

5.

6.

7.

8.

9.

10.

1. Global Need Sat.

2. Autonomy Need Sat. $.164^{* * *}$

3. Competence Need Sat. $.123^{* *} \quad-.048$

4. Relatedness Need Sat. $.111^{* *} \quad-.156^{* *} \quad-.015$

5. Mental Load $\quad .199^{* *} \quad-.030 \quad .163^{* *}$

6. Workload

$\begin{array}{llll}-.002 & .079^{* *} \quad .092^{* *} & -.029\end{array}$

$.628^{* *}$

7. Information

$.548^{* *} \quad .171^{* *}$

$.069^{* *}$

.036

$.272^{* *}$

$.067^{*}$

8. Participation

$.631^{* *} \quad .350^{* *}$

.044

$-.083^{* *}$

$.223^{* *}$

$.150^{* *}$

$.702^{* *}$

9. Colleagues Support $\quad .500^{* *} \quad-.02$

.012

$.497^{* *}$

$.199^{* *}$

$-.041$

$.361^{* *}$

$-.179^{* *}$

$-.331^{* *}$

.035

$-.632^{* *}$

$.288^{* * *}$

$-.139^{* * *}$

$-.517^{* *}$

$-.538^{* * *}$

Note. ${ }^{*} p<.05 ; * * p<.01 ;$ All variables are estimated from factor scores with mean of 0 and a standard deviation of 1. 
Table S8

Correlations between Variables (Sample 2)

1.

4.

5.

6.

7.

8.

9.

10.

1. Global Need Sat.

2. Autonomy Need Sat. $.130^{* *}$

3. Competence Need Sat. $.020 \quad-.223^{* *}$

4. Relatedness Need Sat. $\quad .094^{*} \quad-.157^{* *} \quad-.044$

$\begin{array}{lllll}\text { 5. Scheduling Autonomy } & .630^{* *} & .255^{* *} & -.024 & .008\end{array}$

6. Meaningfulness

$.437^{* *} \quad .165^{* *} \quad .076^{*} \quad .095^{*} \quad .545^{* *}$

7. Task Identity

$.466^{* *} \quad .102^{* *}$

$.082^{*}$

$.102^{* * *}$

$.657^{* *}$

$.486^{* *}$

8. Organizational Support $.645^{* *} \quad .049$

9. Anxiety

$-.226^{* *} \quad .123^{* *} \quad .006$

10. Physical exhaustion $\quad-.349^{* *}$

$-.014 \quad-.016$

$-.187^{* *}$

$.508^{* *}$

$.318^{* * *}$

$.386^{* *}$

Note. $* p<.05 ; * * p<.01$; All variables are estimated from factor scores with mean of 0 and a standard deviation of 1 


\section{Table S9}

Results from the Latent Profile Analysis Models Based on Bifactor Factor Scores

\begin{tabular}{|c|c|c|c|c|c|c|c|c|c|c|}
\hline Model & LL & $\# f \mathrm{p}$ & Scaling & AIC & CAIC & $\mathrm{BIC}$ & ABIC & Entropy & aLMR & BLRT \\
\hline \multicolumn{11}{|l|}{ Sample 1} \\
\hline 1 Profile & -7105.777 & 8 & 1.359 & 14227.553 & 14277.615 & 14269.615 & 14244.202 & $\mathrm{Na}$ & $\mathrm{Na}$ & $\mathrm{Na}$ \\
\hline 2 Profiles & -6979.487 & 13 & 1.431 & 13984.973 & 14066.324 & 14053.324 & 14012.027 & .822 & $<.001$ & $<.001$ \\
\hline 4 Profiles & -6764.281 & 23 & 1.597 & 13574.563 & 13718.490 & 13695.490 & 13622.427 & .862 & .006 & $<.001$ \\
\hline 5 Profiles & -6706.400 & 28 & 1.822 & 13468.801 & 13644.016 & 13616.016 & 13527.070 & .845 & .372 & $<.001$ \\
\hline 6 Profiles & -6662.617 & 33 & 1.732 & 13391.233 & 13597.738 & 13564.738 & 13459.908 & .861 & .254 & $<.001$ \\
\hline 7 Profiles & -6620.208 & 38 & 1.763 & 13316.416 & 13554.209 & 13516.209 & 13395.496 & .865 & .334 & $<.001$ \\
\hline 8 Profiles & -6579.989 & 43 & 1.435 & 13245.978 & 13515.060 & 13472.060 & 13335.464 & .875 & .001 & $<.001$ \\
\hline \multicolumn{11}{|l|}{ Sample 2} \\
\hline 1 Profile & -3565.035 & 8 & 1.250 & 7146.070 & 7190.212 & 7182.212 & 7156.811 & $\mathrm{Na}$ & $\mathrm{Na}$ & $\mathrm{Na}$ \\
\hline 2 Profiles & -3496.188 & 13 & 1.280 & 7018.377 & 7090.107 & 7077.107 & 7035.830 & .814 & $<.001$ & $<.001$ \\
\hline 3 Profiles & -3437.179 & 18 & 1.450 & 6910.357 & 7009.675 & 6991.675 & 6934.523 & .848 & .014 & $<.001$ \\
\hline 4 Profiles & -3416.410 & 23 & 1.560 & 6878.820 & 7005.726 & 6982.726 & 6909.699 & .832 & .354 & $<.001$ \\
\hline 5 Profiles & -3391.439 & 28 & 1.450 & 6838.879 & 6993.373 & 6965.373 & 6876.470 & .856 & .087 & $<.001$ \\
\hline 6 Profiles & -3374.842 & 33 & 1.454 & 6815.683 & 6997.767 & 6964.767 & 6859.988 & .859 & .554 & $<.001$ \\
\hline 8 Profiles & -3343.728 & 43 & 1.281 & 6773.456 & 7010.716 & 6967.716 & 6831.186 & .828 & .198 & $<.001$ \\
\hline \multicolumn{11}{|c|}{ Profile Similarity Across Samples } \\
\hline Configural Similarity & -11499.300 & 47 & 1.566 & 23092.600 & 23605.046 & 23558.046 & 23208.723 & .902 & $\mathrm{Na}$ & $\mathrm{Na}$ \\
\hline Structural Similarity & -11530.075 & 31 & 1.476 & 23122.151 & 23328.232 & 23297.232 & 23198.742 & .904 & $\mathrm{Na}$ & $\mathrm{Na}$ \\
\hline Dispersion Similarity & -11553.180 & 27 & 1.489 & 23160.360 & 23339.850 & 23312.850 & 23227.069 & .903 & $\mathrm{Na}$ & $\mathrm{Na}$ \\
\hline Partial Dispersion Similarity & -11535.653 & 28 & 1.462 & 23127.307 & 23313.445 & 23285.445 & 23196.486 & .903 & $\mathrm{Na}$ & $\mathrm{Na}$ \\
\hline Distribution Similarity & -11538.054 & 25 & 1.526 & 23126.108 & 23293.303 & 23267.303 & 23187.875 & .903 & $\mathrm{Na}$ & $\mathrm{Na}$ \\
\hline
\end{tabular}

Note: LL: Model LogLikelihood; \#fp: Number of free parameters; Scaling: Scaling factor associated with MLR loglikelihood estimates; AIC: Akaïke Information Criteria; CAIC: Constant AIC; BIC: Bayesian Information Criteria; ABIC: Sample-size adjusted BIC; aLMR: Adjusted Lo-Mendel-Rubin likelihood ratio test; BLRT: Bootstrap Likelihood Ratio Test. 

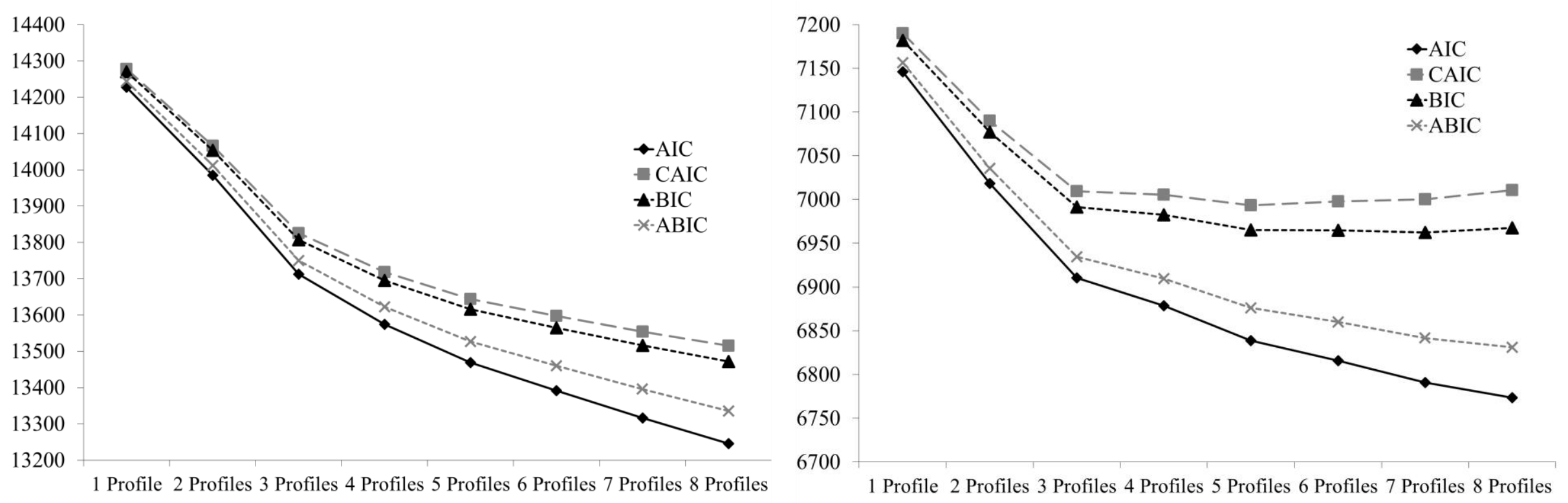

\section{Figure S1}

Elbow Plot of the Value of the Information Criteria for Solutions Including Different Number of Latent Profiles (Based on Bifactor Factor Scores) in Samples 1 (Left) and 2 (Right) 


\section{Table S10}

Results from the Latent Profile Analysis Models Based on First-Order Factor Scores

\begin{tabular}{|c|c|c|c|c|c|c|c|c|c|c|}
\hline Model & $\mathrm{LL}$ & $\# \mathrm{fp}$ & Scaling & AIC & CAIC & $\mathrm{BIC}$ & $\mathrm{ABIC}$ & Entropy & aLMR & BLRT \\
\hline \multicolumn{11}{|l|}{ Sample 1} \\
\hline 1 Profile & -5758.199 & 6 & 1.346 & 11528.398 & 11565.945 & 11559.945 & 11540.885 & $\mathrm{Na}$ & $\mathrm{Na}$ & $\mathrm{Na}$ \\
\hline 2 Profiles & -5092.163 & 10 & 1.658 & 10204.326 & 10266.903 & 10256.903 & 10225.137 & .826 & $<.001$ & $<.001$ \\
\hline 3 Profiles & -4885.859 & 14 & 2.182 & 9799.718 & 9887.326 & 9873.326 & 9828.853 & .834 & .092 & $<.001$ \\
\hline 4 Profiles & -4786.464 & 18 & 3.425 & 9608.929 & 9721.567 & 9703.567 & 9646.388 & .795 & .632 & $<.001$ \\
\hline 5 Profiles & -4730.134 & 22 & 1.791 & 9504.269 & 9641.938 & 9619.938 & 9550.052 & .828 & .016 & $<.001$ \\
\hline 6 Profiles & -4646.537 & 26 & 1.585 & 9345.074 & 9507.774 & 9481.774 & 9299.181 & .796 & .026 & $<.001$ \\
\hline 7 Profiles & -4590.702 & 30 & 1.500 & 9241.403 & 9429.135 & 9399.135 & 9303.835 & .817 & .021 & $<.001$ \\
\hline 8 Profiles & -4451.514 & 34 & 1.418 & 9171.028 & 9383.790 & 9349.790 & 9241.784 & .828 & .002 & $<.001$ \\
\hline \multicolumn{11}{|l|}{ Sample 2} \\
\hline 1 Profile & -2816.042 & 6 & 1.169 & 5644.085 & 5677.191 & 5671.191 & 5652.140 & $\mathrm{Na}$ & $\mathrm{Na}$ & $\mathrm{Na}$ \\
\hline 2 Profiles & -2552.962 & 10 & 1.492 & 5125.923 & 5181.100 & 5171.100 & 5139.349 & .783 & $<.001$ & $<.001$ \\
\hline 3 Profiles & -2470.071 & 14 & 1.513 & 4968.141 & 5045.389 & 5031.389 & 4986.937 & .731 & .020 & $<.001$ \\
\hline 4 Profiles & -2420.567 & 18 & 1.519 & 4877.133 & 4976.451 & 4958.451 & 4901.299 & .766 & .044 & $<.001$ \\
\hline 5 Profiles & -2394.261 & 22 & 1.534 & 4832.522 & 4953.911 & 4931.911 & 4862.058 & .771 & .137 & $<.001$ \\
\hline 6 Profiles & -2369.969 & 26 & 1.757 & 4791.939 & 4935.398 & 4909.398 & 4826.845 & .787 & .544 & $<.001$ \\
\hline 7 Profiles & -2353.952 & 30 & 1.434 & 4767.904 & 4933.434 & 4903.434 & 4808.181 & .756 & .115 & $<.001$ \\
\hline 8 Profiles & -2338.689 & 34 & 1.405 & 4745.378 & 4932.979 & 4898.979 & 4791.025 & .787 & .338 & $<.001$ \\
\hline \multicolumn{11}{|c|}{ Profile Similarity Across Samples } \\
\hline Configural Similarity & -8525.640 & 37 & 2.432 & 17125.280 & 17371.248 & 17334.248 & 17216.695 & .857 & & \\
\hline Structural Similarity & -8565.203 & 25 & 1.782 & 17180.407 & 17346.602 & 17321.602 & 17242.174 & .843 & & \\
\hline Dispersion Similarity & -8576.950 & 22 & 1.812 & 17197.900 & 17344.152 & 17322.152 & 17252.255 & .841 & & \\
\hline Partial Dispersion Similarity & -8572.473 & 23 & 1.741 & 17190.945 & 17343.845 & 17320.845 & 17247.771 & .844 & & \\
\hline Distribution Similarity & -8576.834 & 20 & 1.847 & 17193.668 & 17326.624 & 17306.624 & 17243.082 & .815 & & \\
\hline
\end{tabular}

Note: LL: Model LogLikelihood; \#fp: Number of free parameters; Scaling: Scaling factor associated with MLR loglikelihood estimates; AIC: Akaïke Information Criteria; CAIC: Constant AIC; BIC: Bayesian Information Criteria; ABIC: Sample-size adjusted BIC; aLMR: Adjusted Lo-Mendel-Rubin likelihood ratio test; BLRT: Bootstrap Likelihood Ratio Test. 

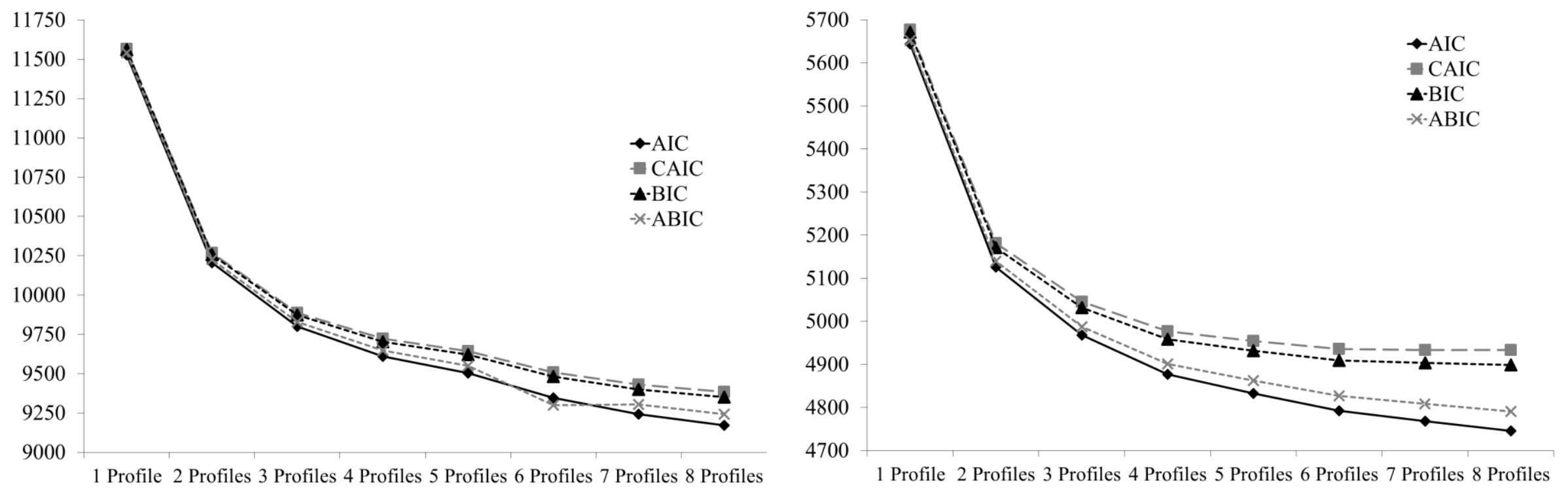

\section{Figure S2}

Elbow Plot of the Value of the Information Criteria for Solutions Including Different Number of Latent Profiles (Based on First-Order Factor Scores) in Samples 1 (Left) and 2 (Right) 


\section{Table S11}

Detailed Parameter Estimates from the Final LPA Solutions (Distributional Similarity with Partial Dispersion Similarity)

\begin{tabular}{|c|c|c|c|c|c|}
\hline & Profile 1 & Profile 2 & Profile 3 & Profile 4 & \\
\hline & Mean $[\mathrm{CI}]$ & Mean $[\mathrm{CI}]$ & Mean $[\mathrm{CI}]$ & Mean $[\mathrm{CI}]$ & Variance $[\mathrm{CI}]$ \\
\hline \multicolumn{6}{|l|}{ Bifactor Factor Scores } \\
\hline Global Need Satisfaction & $.293[.227 ; .359]$ & $-.625[-.796 ;-.455]$ & $-1.649[-1.858 ;-1.440]$ & $-1.261[-1.577 ;-.945]$ & $.560[.492 ; .628]$ \\
\hline Autonomy & $.209[.173 ; .246]$ & $-1.436[-1.573 ;-1.298]$ & $-.552[-.794 ;-.311]$ & $.356[.144 ; .568]$ & $.377[.336 ; .419]$ \\
\hline Competence & $-.019[-.061 ; .023]$ & $.420[.259 ; .582]$ & $-1.111[-1.746 ;-.476]$ & $.022[-.236 ; .280]$ & $.703[.644 ; .761]$ \\
\hline Relatedness & $.051[.002 ; .100]$ & $.315[.165 ; .465]$ & $1.157[.872 ; 1.442]$ & $-1.543[-1.914 ;-1.171]$ & $\begin{array}{l}\text { Sample 1: .385 [.324; .447] } \\
\text { Sample 2: } .592[.510 ; .675]\end{array}$ \\
\hline \multicolumn{6}{|l|}{ First-Order Factor Scores } \\
\hline Autonomy & $-2.280[-2.716 ;-1.844]$ & $-.124[-.308 ; .059]$ & $-1.177[-1.346 ;-1.008]$ & $.695[.619 ; .772]$ & $.407[.358 ; .457]$ \\
\hline Competence & $-2.396[-3.173 ;-1.618]$ & $-.196[-.341 ;-.052]$ & $-1.144[-1.331 ;-.958]$ & $.757[.656 ; .857]$ & $.348[.312 ; .384]$ \\
\hline Relatedness & $-3.350[-4.197 ;-2.502]$ & $-.078[-.217 ; .060]$ & $-1.123[-1.367 ;-.878]$ & $.659[.586 ; .731]$ & $\begin{array}{l}\text { Sample 1: .282 [.239;.326] } \\
\text { Sample 2: .366 [.297;.435] }\end{array}$ \\
\hline
\end{tabular}

Note. $\mathrm{CI}=95 \%$ confidence interval. The profile indicators are estimated from factor scores with mean of 0 and a standard deviation of 1; Profile 1 (Bifactor): Normative profile; Profile 2 (Bifactor): Globally Dissatisfied yet Moderately Competent and Connected profile; Profile 3 (Bifactor): Globally Dissatisfied yet Highly Connected profile; Profile 4 (Bifactor): Globally Dissatisfied yet Moderately Autonomous profile. 


\section{Table S12}

Classification Accuracy: Average Probability of Membership into Each Latent Profile (Column) as a Function of the Most Likely Profile Membership (Row)

\begin{tabular}{|c|c|c|c|c|}
\hline & Profile 1 & Profile 2 & Profile 3 & Profile 4 \\
\hline \multicolumn{5}{|c|}{ Sample 1 (Bifactor) } \\
\hline Profile 1 & .947 & .026 & .007 & .020 \\
\hline Profile 2 & .112 & .844 & .031 & .013 \\
\hline Profile 3 & .063 & .088 & .849 & 0 \\
\hline Profile 4 & .157 & .015 & .005 & .823 \\
\hline \multicolumn{5}{|c|}{ Sample 2 (Bifactor) } \\
\hline Profile 1 & .941 & .028 & .007 & .025 \\
\hline Profile 2 & .120 & .844 & .024 & .012 \\
\hline Profile 3 & .108 & .137 & .721 & .033 \\
\hline Profile 4 & .164 & .033 & .007 & .796 \\
\hline \multicolumn{5}{|c|}{ Sample 1 (First-Order) } \\
\hline Profile 1 & .917 & 0 & .083 & 0 \\
\hline Profile 2 & 0 & .831 & .058 & .112 \\
\hline Profile 3 & .006 & .103 & .891 & 0 \\
\hline Profile 4 & 0 & .125 & 0 & .875 \\
\hline \multicolumn{5}{|c|}{ Sample 2 (First-Order) } \\
\hline Profile 1 & .926 & 0 & .074 & 0 \\
\hline Profile 2 & 0 & .830 & .054 & .116 \\
\hline Profile 3 & .010 & .104 & .886 & 0 \\
\hline Profile 4 & 0 & .109 & 0 & .891 \\
\hline
\end{tabular}

Note. The profile indicators are estimated from factor scores with mean of 0 and a standard deviation of 1; Profile 1 (Bifactor): Normative profile; Profile 2 (Bifactor): Globally Dissatisfied yet Moderately Competent and Connected profile; Profile 3 (Bifactor): Globally Dissatisfied yet Highly Connected profile; Profile 4 (Bifactor): Globally Dissatisfied yet Moderately Autonomous profile. 